\title{
Thermal performance and entropy generation analysis of a high concentration ratio parabolic trough solar collector with $\mathrm{Cu}$-Therminol ${ }^{\circledR}$ VP-1 nanofluid
}

\author{
Aggrey Mwesigye ${ }^{1 \dagger}$, Zhongjie Huan ${ }^{2}$, Josua P. Meyer ${ }^{3}$
}

\begin{abstract}
${ }^{1}$ School of Mechanical, Industrial and Aeronautical Engineering, University of the Witwatersrand, Johannesburg, Private Bag 3, Wits 2050, Johannesburg, South Africa

${ }^{2}$ Department of Mechanical Engineering, Mechatronics and Industrial Design, Tshwane University of Technology, Private Bag X680, Pretoria, 0001, South Africa

${ }^{3}$ Department of Mechanical and Aeronautical Engineering, University of Pretoria, Private Bag X20, Hatfield 0028, South Africa
\end{abstract}

\begin{abstract}
This paper presents results of a numerical study on the thermal and thermodynamic performance of a high concentration ratio parabolic trough solar collector using $\mathrm{Cu}$ Therminol ${ }^{\circledR}$ VP-1 nanofluid as the heat transfer fluid. A parabolic trough system with a concentration ratio of 113 and a rim angle of $80^{\circ}$ has been used in this study. The thermal physical properties of both the base fluid and the copper nanoparticles have been considered temperature dependent. Inlet temperatures in the range $350 \mathrm{~K}$ to $650 \mathrm{~K}$ and flow rates in the range $1.22 \mathrm{~m}^{3} \mathrm{~h}^{-1}$ to $135 \mathrm{~m}^{3} \mathrm{~h}^{-1}$ have been used. The numerical analysis consisted of combined Monte-Carlo ray tracing and computational fluid dynamics procedures. The Monte-Carlo ray tracing procedure is used to obtain the actual heat flux profile on the receiver's absorber tube, which is later coupled to a finite volume based computational fluid dynamics tool to evaluate the thermal and thermodynamic performance of the receiver. Results show that the thermal performance of the receiver improves as the nanoparticle volume fraction increases. The thermal efficiency of the system increases by about $12.5 \%$ as the nanoparticle volume fraction in the base fluid increase from 0 to $6 \%$. The entropy generation rates in the receiver reduce as the nanoparticle volume fraction increases for some range of Reynolds numbers. Above a certain Reynolds number, further increase in the Reynolds numbers makes the entropy generation higher than that of a receiver with only the base fluid.
\end{abstract}

\section{Key words}

Concentration ratio, entropy generation, nanofluid, parabolic trough receiver, thermal efficiency.

\footnotetext{
† Corresponding author: Tel: +27 11717 7378, Fax: +27 117177049

Email address:Aggrey.Mwesigye@wits.ac.za
} 


\section{Nomenclature}

$B e \quad$ Bejan number

$C_{1}, C_{2}, C_{\mu} \quad$ Turbulent model constants

$c_{f} \quad$ Coefficient of friction

$c_{p} \quad$ Specific heat capacity, $\mathrm{J} \mathrm{kg}^{-1} \mathrm{~K}^{-1}$

$C_{R} \quad$ Geometrical concentration ratio $=W_{d} / d_{r o}$

D Tube diameter, $\mathrm{m}$

$d_{g i} \quad$ Glass cover inner diameter, $\mathrm{m}$

$d_{g o} \quad$ Glass cover outer diameter, $\mathrm{m}$

$d_{r i} \quad$ Absorber tube inner diameter, $\mathrm{m}$

$d_{r o} \quad$ Absorber tube outer diameter, $\mathrm{m}$

$f \quad$ Darcy friction factor

$f_{p} \quad$ Focal length, $\mathrm{m}$

G Mass flux, $\mathrm{kg} \mathrm{s}^{-1} \mathrm{~m}^{-2}$

$G_{k} \quad$ Generation of turbulent kinetic energy due to mean velocity gradients, $\mathrm{kg} \mathrm{m}^{-1} \mathrm{~s}^{-3}$

$h \quad$ Heat transfer coefficient, $\mathrm{W} \mathrm{m}^{-2} \mathrm{~K}^{-1}$

$h_{w} \quad$ Outer glass cover heat transfer coefficient, $\mathrm{W} \mathrm{m} \mathrm{m}^{-2} \mathrm{~K}^{-1}$

$I_{b} \quad$ Direct normal irradiance, $\mathrm{W} \mathrm{m}^{-2}$

$k \quad$ Turbulent kinetic energy, $\mathrm{m}^{2} \mathrm{~s}^{-2}$

L Length, $\mathrm{m}$

$\dot{m} \quad$ Mass flow rate, $\mathrm{kg} \mathrm{s}^{-1}$

$\mathrm{Nu} \quad$ Nusselt number

$P \quad$ Pressure, $\mathrm{Pa}$

Pr Prandtl number

$q^{\prime} \quad$ Rate of heat transfer per unit meter, $\mathrm{W} \mathrm{m}^{-1}$

$q^{\prime \prime} \quad$ Heat flux, $\mathrm{W} \mathrm{m} \mathrm{m}^{-2}$

$\dot{q}_{u} \quad$ Useful heat gain, $\mathrm{W}$

Re Reynolds number

$S \quad$ Modulus of the mean rate-of-strain tensor, $\mathrm{s}^{-1}$

$S_{i j} \quad$ Rate of linear deformation tensor, $\mathrm{s}^{-1}$

$S_{\text {gen }} \quad$ Entropy generation rate due to heat transfer and fluid friction in the receiver, $\mathrm{W} \mathrm{K}^{-1}$

$S_{\text {gen }}^{\prime} \quad$ Entropy generation per unit length of the receiver, $\mathrm{W} \mathrm{m}^{-1} \mathrm{~K}^{-1}$

$S^{\prime \prime \prime}$ gen $\quad$ Volumetric entropy generation, $\mathrm{W} \mathrm{m} \mathrm{m}^{-3} \mathrm{~K}^{-1}$

$\left(S^{\prime \prime \prime}{ }_{g e n}\right)_{F} \quad$ Volumetric entropy generation due to fluid friction, $\mathrm{W} \mathrm{m} \mathrm{m}^{-3} \mathrm{~K}^{-1}$ 
$\left(S^{\prime \prime \prime}{ }_{\text {gen }}\right)_{H} \quad$ Volumetric entropy generation due to heat transfer, $\mathrm{W} \mathrm{m} \mathrm{m}^{-3} \mathrm{~K}^{-1}$

$T \quad$ Temperature, $\mathrm{K}$

$u_{m} \quad$ Mean flow velocity, $\mathrm{m} \mathrm{s}^{-1}$

$u_{i}, u_{j} \quad$ Velocity components, $\mathrm{m} \mathrm{s}^{-1}$

$u^{\prime}, v^{\prime}, w^{\prime} \quad$ Velocity fluctuations, $\mathrm{m} \mathrm{s}^{-1}$

V Volume, $\mathrm{m}^{3}$

$V_{w} \quad$ Wind velocity, $\mathrm{m} \mathrm{s}^{-1}$

$\dot{V} \quad$ Volumetric flow rate, $\mathrm{m}^{3} \mathrm{~s}^{-1}$

$W_{a} \quad$ Parabolic trough aperture width, $\mathrm{m}$

$\dot{W}_{p} \quad$ Pumping power, $W$

$x_{i}, x_{j} \quad$ Spatial coordinates, $\mathrm{m}$

$x, y, z \quad$ Cartesian coordinates, $\mathrm{m}$

$y^{+} \quad$ Dimensionless wall coordinate

$-\rho \overline{u_{i}^{\prime} u_{j}^{\prime}} \quad$ Reynolds stresses, $\mathrm{N} \mathrm{m}^{-2}$

$\triangle P \quad$ Pressure drop, $\mathrm{Pa}$

\section{Greek letters}

$\alpha$

$\alpha_{t} \quad$ Turbulent thermal diffusivity, $\mathrm{m}^{2} \mathrm{~s}^{-1}$

$\alpha_{a b s} \quad$ Absorber tube absorptivity

$\sigma_{h . t} \quad$ Turbulent Prandtl number for energy

$\sigma_{\varepsilon} \quad$ Turbulent Prandtl number for $\varepsilon$

$\sigma_{k} \quad$ Turbulent Prandtl number for $k$

$\sigma_{\text {mirror }} \quad$ Collector specularity error, mrad

$\sigma_{\text {slope }} \quad$ Collector slope error, $\mathrm{mrad}$

$\sigma_{\text {sun }} \quad$ Sun shape parameter (Sun error), $\mathrm{mrad}$

$\delta_{i j} \quad$ Kronecker delta

$\varepsilon \quad$ Turbulent dissipation rate, $\mathrm{m}^{2} \mathrm{~s}^{-3}$

$\varepsilon_{g} \quad$ Glass cover emissivity

$\varepsilon_{r o} \quad$ Absorber tube coating emissivity

$\eta \quad$ Turbulence model parameter $=S k / \varepsilon$

$\eta_{t h} \quad$ Thermal efficiency, $\%$

$\eta_{e l} \quad$ Electrical efficiency, $\%$

$\phi \quad$ Nanoparticle volume fraction in the base fluid, $\%$

$\varphi_{r} \quad$ Rim angle, degrees 


$\begin{array}{ll}\rho & \text { Density, } \mathrm{kg} \mathrm{m}^{-3} \\ \rho & \text { Mirror reflectivity } \\ \tau_{w} & \text { Wall shear stress, } \mathrm{N} \mathrm{m}^{-2} \\ \tau_{g} & \text { Glass cover transmissivity } \\ \lambda & \text { Fluid thermal conductivity, } \mathrm{W} \mathrm{m} \mathrm{m}^{-1} \mathrm{~K}^{-1} \\ \mu & \text { Viscosity, } \mathrm{Pa} \mathrm{s} \\ \mu_{t} & \text { Eddy viscosity, } \mathrm{Pa} \mathrm{s} \\ u_{\tau} & \text { Friction velocity }\left(u_{\tau}=\sqrt{\tau_{w} / \rho}\right), \mathrm{m} \mathrm{s}^{-1} \\ v & \text { Kinematic viscosity, } \mathrm{m}^{2} \mathrm{~s}^{-1}\end{array}$

\section{Subscripts}

$\begin{array}{ll}\text { amb } & \text { Ambient state } \\ b & \text { Base fluid } \\ b u l k & \text { Bulk fluid state } \\ F & \text { Fluid friction irreversibility } \\ g i & \text { Glass cover inner wall } \\ g o & \text { Glass cover outer wall } \\ H & \text { Heat transfer irreversibility } \\ i, j, k & \text { General spatial indices } \\ \text { inlet } & \text { Inlet conditions } \\ n f & \text { Nanofluid } \\ \text { outlet } & \text { Outlet conditions } \\ p & \text { Nanoparticle } \\ r i & \text { Absorber tube inner wall } \\ r i & \text { Absorber tube outer wall } \\ s k y & \text { Sky } \\ t & \text { Turbulent } \\ w & \text { Wall }\end{array}$

\section{Superscripts}

_ $\quad$ Time averaged value

' Fluctuation from mean value

Dimensionless parameter 


\section{Introduction}

The growing concerns of climate change and the need to keep the increase in temperatures below $2^{\circ} \mathrm{C}$ relative to pre-industrial levels, to avoid the catastrophic effects of climate change from global warming, has increased the need to develop and deploy clean sources of energy [1]. It is globally accepted that the use of fossil based fuels has increased the emission of $\mathrm{CO}_{2}$ to the atmosphere, the primary cause of global warming and climate change. To limit the emission of $\mathrm{CO}_{2}$, the rate of use of fossil fuels will need to be decelerated considerably, while the use of clean and renewable energy resources will need to be increased significantly. Of the available renewable energy resources, solar energy is shown to have significant potential to supply a significant portion of the world's energy demand [2]. Solar energy is generally widely available and can be harnessed with little or no impact on the environment.

Electricity generation using solar thermal systems is advantageous compared to electricity generation using solar photovoltaic systems, since it is easier to store heat than electricity. With solar thermal systems, energy can be stored when the sun is out and dispatched during times when there is no sun. The parabolic trough system is one of the most commercially and technically developed of the available solar thermal systems. The parabolic trough technology accounts for over $90 \%$ of the electrical energy generated from solar thermal systems [3]. A recent list of parabolic trough based solar power plants and their respective capacities is provided by Jebasingh [4].

To further reduce the cost of energy from solar thermal systems and make them cost competitive with that from coal power plants, several research and development initiates are still underway $[5,6]$. With these research and development initiatives, the cost of electricity from these systems has continued to decrease. Moreover, with continued research and development efforts, the cost of electricity from these systems is predicted to become competitive with medium-sized gas plants in the near future [7]. With these advances, aperture sizes of parabolic trough systems are increasing, leading to high concentration ratio systems [6,8]. With large aperture sizes, less drives, connections and controls are used leading to reduced installation, operation and maintenance costs. One of the large concentration ratio parabolic trough systems is the Ultimate Trough ${ }^{\circledR}$ with an aperture of 7.5 $\mathrm{m}$ and a solar collector assembly length of $247 \mathrm{~m}$ [8]. This collector is expected to reduce the solar field cost by 20 to $25 \%$ [8]. 
As the concentration ratios increase, it can be expected that the receiver thermal loss and heat transfer irreversibilities will increase due to the high temperatures and temperature gradients at these high concentration ratios [9-11]. To improve the thermal performance of the receiver as the concentration ratios increase, heat transfer enhancement will play a significant role. Already a number of studies have shown that significant improvements in receiver thermal performance can be obtained with heat transfer enhancement [12-16]. Selected studies on heat transfer enhancement techniques in parabolic trough receivers include: The use of inserts inside the receiver's absorber tube was investigated by Mwesigye et al. [16,17], the use of porous discs was studied by Ravi Kumar and Reddy [13]. In another study, Ravi Kumar and Reddy investigated the use of different fin configurations for heat transfer enhancement in a parabolic trough receiver [12]. Muñoz and Abánades [14] showed that using internal helical fins on the receiver's absorber tube, the absorber tube temperatures can be reduced between 15.3 and $40.9 \%$. Song et al. [18] studied the performance of a parabolic trough receiver with a helical screw tape insert. From these studies, it has been shown that heat transfer enhancement improves receiver thermal and thermodynamic performance. The increase in heat transfer performance is attributed to improved heat transfer from the absorber tube to the heat transfer fluid with heat transfer enhancement as well as due to reduced absorber tube temperatures leading to reduced receiver thermal losses.

Recently, nanofluids have received considerable attention for use in heat transfer devices. Nanofluids are simply engineered diluted colloidal suspensions of particles with sizes in the nanoscale range (less than $100 \mathrm{~nm}$ ) in a base fluid [19]. Including nanoparticles in the base fluid significantly improves the thermal transport properties of the base fluid. The heat transfer performance achieved with nanofluids is shown to greatly surpass the performance with heat transfer liquids available today [20,21]. The use of nanofluids has recently found applications in solar thermal systems. Javadi et al. [22] presented an extensive review on the performance of solar collectors using nanofluids. A recent review on the application of nanofluids in solar collectors was presented by Verma and Tiwari [23]. The extensive applications of nanofluids for solar energy applications can be seen from these reviews. Several researchers have investigated the use of nanofluids in flat plate solar collectors, evacuated tube solar collectors and other non-concentrating solar collectors [24-33].

A number of researchers have also investigated the use of nanofluids in parabolic trough systems. Taylor et al. [34] compared a nano-based concentrated solar thermal system with a conventional one. The efficiency was shown to increase between 5 and $10 \%$ with the use of 
nanofluids. Waghole et al. [35] experimentally investigated the performance of a parabolic trough system with silver nanofluids in the absorber/receiver with twisted tape inserts. Recently, Sokhansefat et al. [36] investigated heat transfer enhancement in a parabolic trough collector tube using a synthetic oil- $\mathrm{Al}_{2} \mathrm{O}_{3}$ nanofluid for nanoparticle concentrations less than $5 \%$ and operating temperatures of $300 \mathrm{~K}, 400 \mathrm{~K}$ and $500 \mathrm{~K}$. They showed that the heat transfer performance increases as the volumetric concentration of nanoparticles increases. The heat transfer performance due to the use of the nanofluids was also found to decrease as the operating temperatures increased. In a recent study, Mwesigye et al. [37] numerically investigated the thermodynamic performance of a parabolic trough system with syltherm800$\mathrm{Al}_{2} \mathrm{O}_{3}$ nanofluid. The thermal efficiency of the system was shown to increase up to $7.6 \%$.

From the reviewed literature, the potential for improved performance of parabolic trough systems with heat transfer enhancement is evident. In addition to improved receiver thermal performance, heat transfer enhancement is shown to reduce thermal strains in the receiver tube thereby improving its reliability [38]. The use of nanofluids for heat transfer enhancement of parabolic trough systems has not been widely investigated. Moreover, the performance of these systems will depend on the combination of nanoparticles and base fluid used, since different materials will have different properties. Copper nanoparticles have significantly higher thermal conductivity i.e. about $401 \mathrm{~W} \mathrm{~m}^{-1} \mathrm{~K}^{-1}$ at $300 \mathrm{~K}$ and $395 \mathrm{~W} \mathrm{~m}^{-1}$ $\mathrm{K}^{-1}$ at $373 \mathrm{~K}$ [39] compared to the thermal conductivity of $\mathrm{Al}_{2} \mathrm{O}_{3}$ nanoparticles of $36 \mathrm{~W} \mathrm{~m}^{-1}$ $\mathrm{K}^{-1}$ at $300 \mathrm{~K}$ [40]. In this study, thermal and thermodynamic performance of a parabolic trough system using $\mathrm{Cu}$-Therminol ${ }^{\circledR} \mathrm{VP}-1$ nanofluid is investigated numerically. Moreover, the application of the second law of thermodynamics using the entropy generation method ensures that the irreversibilities in the receiver are accounted for. To the authors' best knowledge, the study of the thermal performance and the thermodynamic analysis using the second law of thermodynamics of a high concentration ratio parabolic trough solar collector using $\mathrm{Cu}$-Therminol ${ }^{\circledR} \mathrm{VP}-1$ nanofluid has not been done before.

\section{Physical model}

A parabolic trough system consists of a collector in the form of a parabolically shaped mirror that collects the incident solar radiation and reflects it onto a receiver tube that is placed at the focal point of the parabola as shown in Fig. 1. For a mirror of perfect shape and with no optical errors, rays perpendicular to the collector's aperture are reflected to the focal point of the parabola. The collector considered in this study has a rim angle $\left(\varphi_{r}\right)$ of $80^{\circ}$, an aperture width $\left(W_{a}\right)$ of $9 \mathrm{~m}$ and a length of $5 \mathrm{~m}$. The receiver tube consists of a steel absorber tube that 


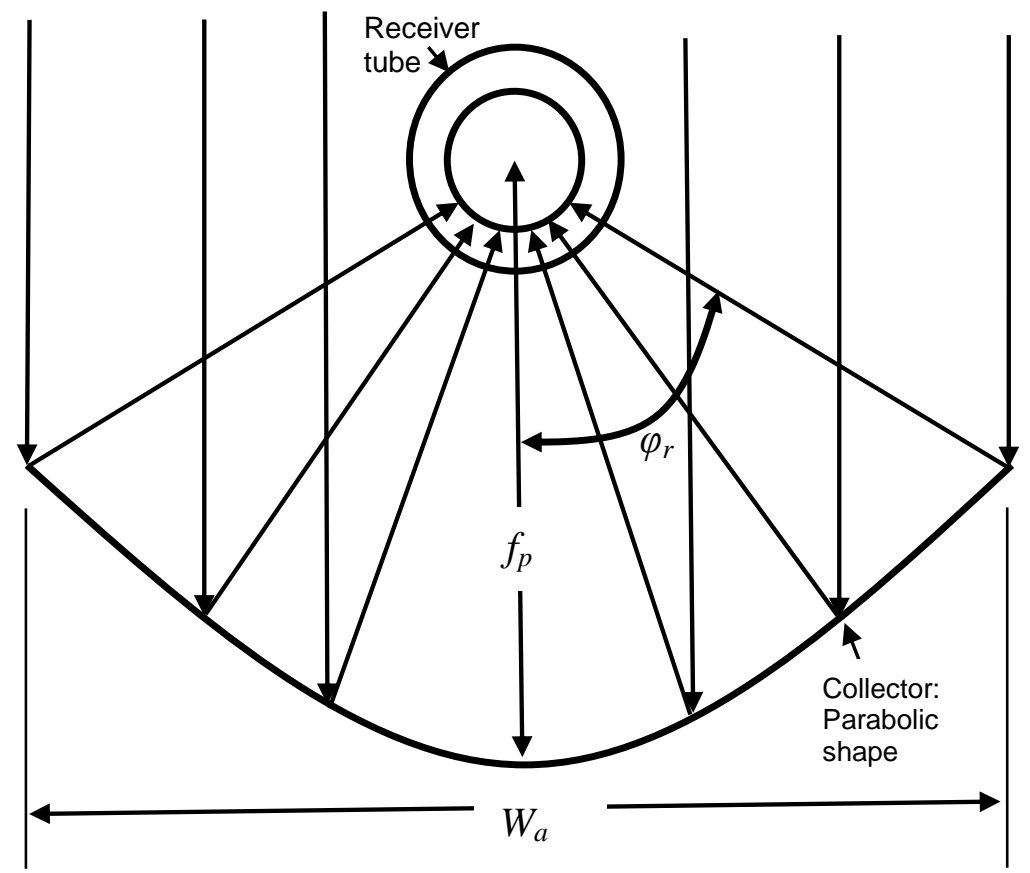

Fig.1. Parabolic trough solar collector with some of the incident and reflected rays.

is enclosed by a glass cover. In conventional receiver tubes, such as the ones used in power generation plants, the annulus space between the absorber tube and glass cover is evacuated to very low pressures of about $0.0103 \mathrm{~Pa}$ [3] to suppress the convection heat loss. In addition, the absorber tube is selectively coated, making it highly absorptive to lowwavelength incoming solar radiation, and with less emission of high-wavelength infrared radiation. The two-dimensional representations of the receiver's cross-section is shown in Fig. 2(a). The receiver tube used in this study has properties similar to those of the Schott's PTR70 receiver [41]. The absorber tube outer diameter was taken as $80 \mathrm{~mm}$ and the glass cover outer diameter was $125 \mathrm{~mm}$. The receiver thermal model can be represented by a thermal resistance network as shown in Fig. 2(b) using the notation in Fig. 2(a). There is heat transfer by conduction through the absorber tube inner wall at a temperature $T_{r i}$ to the absorber tube outer wall at a temperature $T_{r o}$, then heat is transferred by combined radiation and convection through the annulus space between the absorber tube and the glass cover to the inner wall of the glass cover at $T_{g i}$, then by conduction through the glass cover to the outer wall of the glass cover at a temperature $T_{g o}$ and finally to the surroundings by combined forced convection and radiation. For a receiver whose annulus space is evacuated to very low pressures, the convective heat loss term between the absorber tube and the glass cover becomes very small and can be neglected [3]. Detailed thermal modelling and measurement 

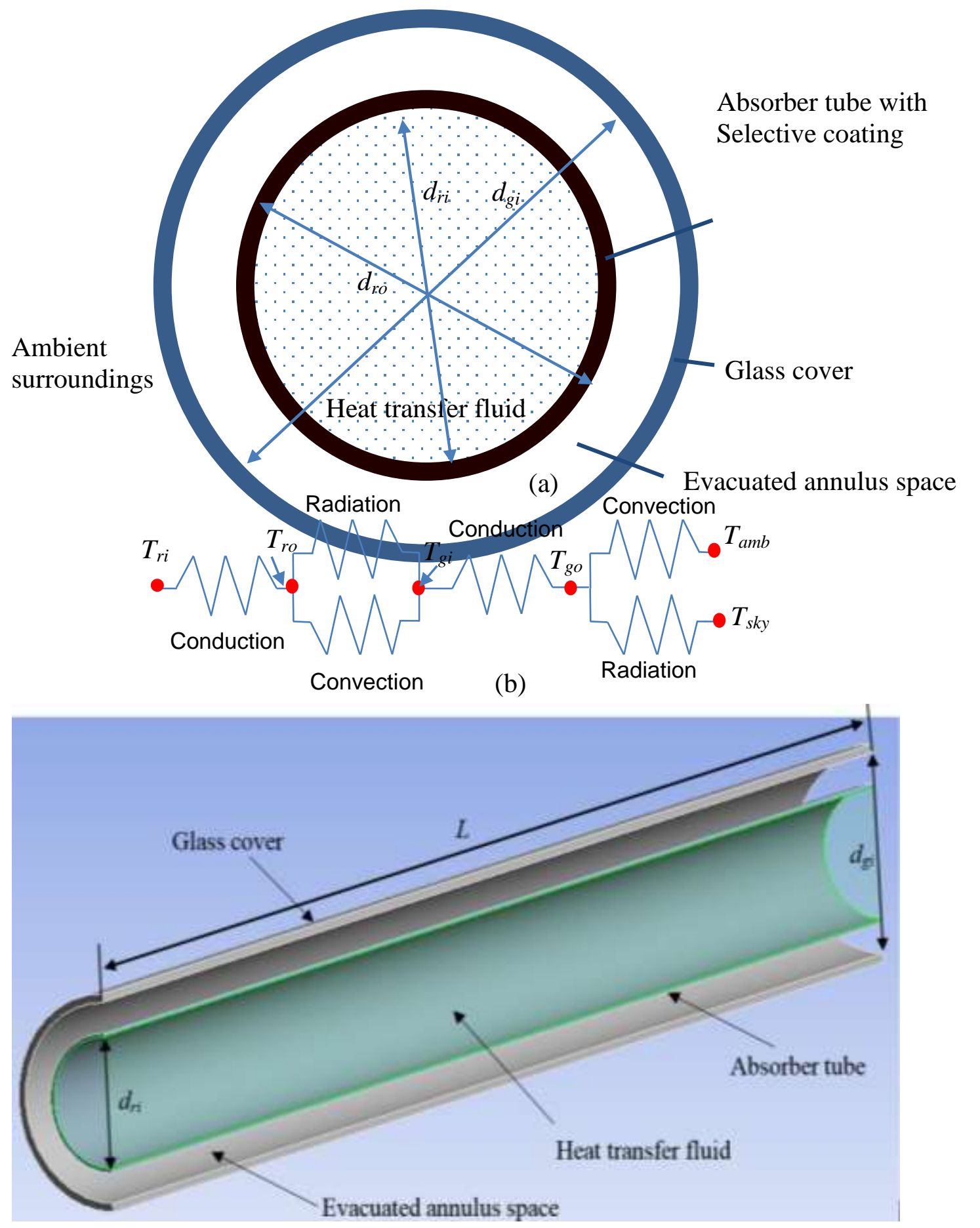

(c)

Fig. 2. Parabolic trough receiver physical models (a) Receiver cross-section, (b) representative receiver thermal loss thermal network, and (c) computational domain used in the numerical analysis.

of receiver thermal loss can be found in studies by Foristall [42] and Burkholder and Kutscher $[9,10]$. In this work, the thermal and thermodynamic performance of the receiver is investigated numerically. The computational domain used for this purpose is shown in Fig.2(c). Given the symmetrical nature of the heat flux incident on the receiver's absorber tube, only half the receiver is used in the numerical modelling. 


\section{Mathematical modelling}

\subsection{Governing equations}

With the high concentration ratio considered in this study, flow rates inside the receiver's absorber tube are selected to give turbulent flow conditions for better heat transfer performance. For turbulent flow and steady state conditions used, the general governing equations are the Reynolds averaged Navier-Stokes equations given by [43]

Continuity

$\frac{\partial\left(\rho \bar{u}_{i}\right)}{\partial x_{i}}=0$

Momentum equation

$$
\frac{\partial}{\partial x_{j}}\left(\rho \bar{u}_{i} \bar{u}_{j}\right)=-\frac{\partial \bar{P}}{\partial x_{i}}+\frac{\partial}{\partial x_{j}}\left[\mu\left(\frac{\partial \bar{u}_{i}}{\partial x_{j}}+\frac{\partial \bar{u}_{j}}{\partial x_{i}}\right)-\frac{2}{3} \mu \frac{\partial \bar{u}_{i}}{\partial x_{i}} \delta_{i j}-\rho \overline{u_{i}^{\prime} u_{j}^{\prime}}\right]
$$

Energy equation

$$
\frac{\partial}{\partial x_{j}}\left(\rho \bar{u}_{j} c_{p} \bar{T}\right)=\frac{\partial}{\partial x_{j}}\left(\lambda \frac{\partial \bar{T}}{\partial x_{j}}+\frac{\mu_{t}}{\sigma_{h, t}} \frac{\partial\left(c_{P} \bar{T}\right)}{\partial x_{j}}\right)+\bar{u}_{j} \frac{\partial \bar{P}}{\partial x_{j}}+\left[\mu\left(\frac{\partial \bar{u}_{i}}{\partial x_{j}}+\frac{\partial \bar{u}_{j}}{\partial x_{i}}\right)-\frac{2}{3} \mu \frac{\partial \bar{u}_{i}}{\partial x_{i}} \delta_{i j}-\rho \overline{u_{i}^{\prime} u_{j}^{\prime}}\right] \frac{\partial \bar{u}_{i}}{\partial x_{j}}
$$

The Reynolds stresses in Eqs. (2) and (3) are related to strain according to [43]

$$
-\overline{\rho u_{i}^{\prime} u_{j}^{\prime}}=\mu_{t}\left(\frac{\partial \bar{u}_{i}}{\partial x_{j}}+\frac{\partial \bar{u}_{j}}{\partial x_{i}}\right)-\frac{2}{3}\left(\rho k+\mu_{t} \frac{\partial \bar{u}_{k}}{\partial x_{k}}\right) \delta_{i j}
$$

In which $k$ is the turbulent kinetic energy given by [43]

$$
k=\frac{1}{2}\left(\overline{u^{\prime 2}}+\overline{v^{\prime 2}}+\overline{w^{\prime 2}}\right)
$$

The realisable $k-\varepsilon$ model was used for turbulence closure [44]. The realisable $k-\varepsilon$ model requires two additional equations for the turbulent kinetic energy $(k)$ and turbulent dissipation rate $(\varepsilon)$.

The transport equation for the turbulent kinetic energy is $[43,44]$

$$
\frac{\partial}{\partial x_{j}}\left(\rho k \bar{u}_{j}\right)=\frac{\partial}{\partial x_{j}}\left[\left(\mu+\frac{\mu}{\sigma_{k}}\right) \frac{\partial k}{\partial x_{j}}\right]+G_{k}-\rho \varepsilon
$$


and the turbulent dissipation rate $(\varepsilon)$ is given by $[43,44]$

$$
\frac{\partial}{\partial x_{j}}\left(\rho \varepsilon \bar{u}_{j}\right)=\frac{\partial}{\partial x_{j}}\left[\left(\mu+\frac{\mu_{t}}{\sigma_{\varepsilon}}\right) \frac{\partial \varepsilon}{\partial x_{j}}\right]+\rho C_{1} S \varepsilon-\rho C_{2} \frac{\varepsilon^{2}}{k+\sqrt{v \varepsilon}}
$$

Where $G_{k}$ is the production of turbulent kinetic energy given by

$$
G_{k}=-\rho \overline{u_{i}^{\prime} u_{j}^{\prime}} \frac{\partial \bar{u}_{j}}{\partial x_{i}}
$$

From Eq. (8), the production of turbulent kinetic energy $\left(G_{k}\right)$ can be obtained as:

$G_{k}=\mu_{t} S^{2}$

The eddy viscosity is given by [43]

$$
\mu_{t}=\rho C_{\mu} \frac{k^{2}}{\varepsilon}
$$

The details of the realisable $k-\varepsilon$ and the detailed determination of $C_{\mu}$ are given in ANSYS ${ }^{\circledR}$ [43]. The model constants in the realisable $k-\varepsilon$ model are

$C_{1}=\max \left[0.43, \frac{\eta}{\eta+5}\right], \quad \eta=S \frac{k}{\varepsilon}, S \equiv \sqrt{2 S_{i j} S_{i j}}, C_{2}=1.9, \sigma_{k}=1, \sigma_{\varepsilon}=1.2 . S_{i j}$ represents the rate of linear deformation of a fluid element. In total, there are nine components in three dimensions. Three of these components are linear elongation deformation components and six are shearing and deformation components [43].

\subsection{Determination of local entropy generation rates}

Given the non-uniform distribution of the heat flux on the receiver's absorber tube, the entropy generation has been determined numerically and locally using the methodology proposed by Kock and Herwig $[45,46]$. The entropy generation rates are determined from the known velocity and temperature fields obtained from the computational fluid dynamics analysis. Using this method, the entropy generation is determined as a sum of the heat transfer and the fluid friction irreversibility as

$$
S_{g e n}^{\prime \prime \prime}=\left(S_{g e n}^{\prime \prime \prime}\right)_{F}+\left(S_{g e n}^{\prime \prime \prime}\right)_{H}
$$


The entropy generation due to the fluid friction irreversibility $\left(S^{\prime \prime \prime}{ }_{\text {gen }}\right)_{F}$ is given by $[45,46]$

$$
\left(S_{g e n}^{\prime \prime \prime \prime}\right)_{F}=\frac{\mu}{\bar{T}}\left(\frac{\partial \bar{u}_{i}}{\partial x_{j}}+\frac{\partial \bar{u}_{j}}{\partial x_{i}}\right) \frac{\partial \bar{u}_{i}}{\partial x_{j}}+\frac{\rho \varepsilon}{\bar{T}}
$$

The first term in Eq. (12) is the entropy produced by direct dissipation and the last term is the entropy produced by indirect (turbulent) dissipation.

The entropy generation due to the heat transfer irreversibility $\left(S_{g e n}^{\prime \prime \prime}\right)_{H}$, is given by $[45,46]$

$$
\left(S_{g e n}^{\prime \prime \prime}\right)_{H}=\frac{\lambda}{\bar{T}^{2}}(\nabla \bar{T})^{2}+\frac{\alpha_{t}}{\alpha} \frac{\lambda}{\bar{T}^{2}}(\nabla \bar{T})^{2}
$$

In Eq. (13), the first term is the entropy produced by heat transfer with mean temperatures and the last term is the entropy produced by heat transfer with fluctuating temperatures due to turbulence. In both terms, $(\lambda)$ is the fluid thermal conductivity while $(\alpha)$, and $\alpha_{t}$ in the last term are the thermal diffusivities.

Equations (11) - (13) determine the local entropy generation rate in each computational cell in the computational domain. The total entropy generation rate is the sum of the entropy generation rates for all computational cells making up the entire computational domain. This is given by the integral of the volumetric entropy generation rate for the entire computational domain of a fluid occupying a volume, $V$ as

$$
S_{g e n}=\iiint_{V} S_{g e n}^{\prime \prime \prime} d V
$$

To compare results of the numerical study with analytically obtained results, the expression presented by Bejan [47] can be used. The entropy generation is also a sum of the heat transfer irreversibility and the fluid friction irreversibility as [47]

$$
S_{g e n}^{\prime}=\frac{q^{\prime 2}}{\pi \lambda T_{b u l k}^{2} N u}+\frac{32 \dot{m}^{3} c_{f}}{\pi^{2} \rho^{2} T_{b u l k} D^{5}}
$$

Where $\dot{m}$ is the mass flow rate, $D$ is the tube diameter, $q^{\prime}$ is the heat transfer rate per unit length, $\quad N u=h D / \lambda$ with $h=q^{\prime \prime} /\left(T_{w}-T_{b u l k}\right), c_{f}=(-d p / d x) \rho D / 2 G^{2}$, with $G=4 \dot{m} / \pi D^{2}$ and $T_{b u l k}$ is the bulk fluid temperature $\left(T_{\text {inlet }}+T_{\text {outlet }}\right) / 2$. The first term in Eq. (15) is the entropy generation 
due to the heat transfer irreversibility, and the second term is the entropy generation due to the fluid friction irreversibility.

\subsection{Thermophysical properties of the heat transfer fluid}

The nanofluid used as the heat transfer fluid is made up of copper nanoparticles and Therminol ${ }^{\circledR} \mathrm{VP}-1$ as the base fluid. The properties of both copper and Therminol ${ }^{\circledR} \mathrm{VP}-1$ are taken to be temperature dependent. The properties of Therminol ${ }^{\circledR} \mathrm{VP}-1$ are taken from the manufacturer's data sheets [48]. From this technical bulletin, polynomials were derived for the properties of Therminol ${ }^{\circledR} \mathrm{VP}-1$ for temperatures in the range $285.15 \mathrm{~K}$ to $698.15 \mathrm{~K}$ as given in Eqs. (16) - (20).

The density is given by

$\rho=1.4386 \times 10^{3}-1.8711 T+2.737 \times 10^{-3} T^{2}-2.3793 \times 10^{-6} T^{3}\left(\mathrm{~kg} \mathrm{~m}^{-3}\right)$

The thermal conductivity is given by

$$
\lambda=0.14644+2.0353 \times 10^{-5} T-1.9367 \times 10^{-7} T^{2}+1.0614 \times 10^{-11} T^{3}\left(\mathrm{~W} \mathrm{~m}^{-1} \mathrm{~K}^{-1}\right)
$$

The specific heat capacity is given by

$$
c_{p}=2.125 \times 10^{3}-11.017 T+0.049862 T^{2}-7.7663 \times 10^{-5} T^{3}+4.394 \times 10^{-8} T^{4}\left(\mathrm{~J} \mathrm{~kg}^{-1} \mathrm{~K}^{-1}\right)
$$

The viscosity is given by a piece-wise polynomial. For $285.15 \mathrm{~K} \leq T \leq 373.15 \mathrm{~K}$

$\mu=3.661 \times 10^{2}-3.0154 T+8.3409 \times 10^{-3} T^{2}-7.723 \times 10^{-6} T^{3}(\mathrm{mPa} \mathrm{s})$

and for $373.15 \mathrm{~K} \leq T \leq 698.15 \mathrm{~K}$

$\mu=23.165-0.1476 T+3.617 \times 10^{-4} T^{2}-3.9844 \times 10^{-7} T^{3}+1.6543 \times 10^{-10} T^{4}(\mathrm{mPa} \mathrm{s})$

The thermal conductivity and specific heat capacity of copper are given by polynomials derived from property tables in Incropera et al. [39] as given by Eq. (21) and (22). The density of copper was taken as $8933 \mathrm{~kg} \mathrm{~m}^{-3}$ [39].

The thermal conductivity is given by

$$
\lambda=441.6-0.17119 T+1.5446 \times 10^{-4} T^{2}-7.2917 \times 10^{-8} T^{3} \quad\left(\mathrm{~W} \mathrm{~m}^{-1} \mathrm{~K}^{-1}\right)
$$

The specific heat capacity is given by

$$
c_{p}=285.8+0.44631 T-5.2054 \times 10^{-4} T^{2}+2.3958 \times 10^{-7} T^{3} \quad\left(\mathrm{~J} \mathrm{~kg}^{-1} \mathrm{~K}^{-1}\right)
$$

The resulting $\mathrm{Cu}$-Therminol ${ }^{\circledR} \mathrm{VP}-1$ nanofluid will have properties that are dependent on the properties of both the nanoparticles used and the base fluid in which they are suspended. A single-phase model was adopted in this study to predict the thermal and thermodynamic performance of the parabolic trough receiver with $\mathrm{Cu}$-Therminol ${ }^{\circledR} \mathrm{VP}-1$ nanofluid. The 
single-phase modelling approach is said to give reasonably accurate results for both low nanoparticle concentrations and for nanoparticle diameters smaller than $100 \mathrm{~nm}[49,50]$. The density was determined from the classic formula for conventional solid-liquid mixtures. Whereas, the specific heat capacity was determined from the commonly used expression that assumes thermal equilibrium between particles and the surrounding liquid [51,52].

The nanofluid density is given by $[51,52]$

$\rho_{n f}=(1-\phi) \rho_{b}+\phi \rho_{p}$

The nanofluid specific heat capacity is given by [51-53]

$c_{p_{n f}}=\frac{(1-\phi) c_{p_{b}} \rho_{b}+\phi c_{p p} \rho_{p}}{(1-\phi) \rho_{b}+\phi \rho_{p}}$

Several models for determining the viscosity of nanofluids are available in literature. There are generally significant deviations between different models. For nanoparticle volume fractions above $2 \%$, the Einstein's model underestimates the viscosity. Therefore, in this work a model of viscosity obtained by precise least square curve fitting of experimental data [52-55] that gives slightly higher values viscosity than those of the Einstein's model was used. It gives values of viscosity higher than those of the Einstein's model at high volume fractions and approaches the Einstein's model at low values of volume fraction. Accordingly, the dynamic viscosity is given by [52-55]

$\mu_{n f}=\mu_{b}\left(123 \phi^{2}+7.3 \phi+1\right)$

The Bruggeman model [52,56], which considers interaction among spherical particles with various concentrations of inclusion, was used for modelling thermal conductivity of the nanofluid. The thermal conductivity obtained with the Bruggeman model compares very well with Maxwell's model of the classic effective medium theory which was shown to be accurate for well-dispersed particles in a benchmark study of thermal conductivities of nanofluids [57]. The Bruggeman model is applicable over a wide range of nanoparticle volume fractions, at low values of volume fraction, it gives values of thermal conductivity similar to those of the Maxwell's model.

The Bruggeman model gives the thermal conductivity as [52,56]

$$
\lambda_{n f}=0.25\left[(3 \phi-1) \lambda_{p}+(2-3 \phi) \lambda_{b}+\sqrt{\Delta}\right]
$$


Where

$$
\Delta=\left[(3 \phi-1) \lambda_{p}+(2-3 \phi) \lambda_{b}\right]^{2}+8 \lambda_{p} \lambda_{b}
$$

\section{Boundary conditions}

\subsection{Absorber tube heat flux profile}

The actual thermal performance of the entire parabolic trough collector requires the use of realistic system geometrical and optical parameters. The realistic heat flux profile on the receiver's absorber tube is non-uniform in the tube's circumferential direction $[11,14]$. Similar to previous investigations[11,16,37], this profile was obtained using ray tracing implemented in SolTrace, an open source ray tracing software developed by the National Renewable Energy Laboratory (NREL) [58]. In the ray tracing procedure, the sun shape was taken as Gaussian distribution with $\sigma_{\text {sun }}=2.6 \mathrm{mrad}$ [58], the maximum number of sun generated rays was set to $10^{8}$, and the desired number of ray intersections was set to $10^{6}$. A slope error of $3 \mathrm{mrad}$ and a specularity error of $0.5 \mathrm{mrad}$ were used for the parabolic trough mirror. These values are close to those in actual systems. In an optical characterisation of parabolic trough systems [59], the average slope error of about $3.4 \mathrm{mrad}$ was achieved. The other geometrical parameters of the parabolic trough system used are given in Table 1 . The validation of the ray tracing results was done in previous studies by Mwesigye et al. $[11,60]$ and will not be presented again.

In this study, a rim angle of $80^{\circ}$ and a geometrical concentration ratio of 113 were used. The geometrical concentration ratio was selected to give a system with a high concentration ratio compared to currently used commercial systems which have geometrical concentration ratios of about 82 [3]. Moreover, high concentration ratio systems are under development to reduce the cost of energy from parabolic trough solar collector technology such as the Ultimate Trough $^{\circledR}[8]$ and the SkyTrough ${ }^{\circledR}$ [61]. A rim angle of $80^{\circ}$ was shown to be an angle beyond which there are no significant reductions in heat flux peaks and entropy generation rates [11]. A direct normal irradiance (DNI) of $1000 \mathrm{~W} \mathrm{~m}^{-2}$ was used in this study. The obtained heat flux profile was coupled to a computational fluid dynamics code as a heat flux boundary condition using a user-defined function. The heat flux distribution on the receiver's absorber tube is generally non-uniform and depends on the geometry of the collector and several optical errors present in the system. The dependence of heat flux on collector rim angle and concentration ratio was presented in Mwesigye et al. [11]. Sample variation of heat flux 
around the absorber tube's circumference at different values of collector slope errors and mirror specularity errors is shown in Fig. 3. Generally, as slope errors increase less of the reflected rays will be intercepted by the receiver and thus the peak heat flux and average heat flux on the absorber tube reduce as shown in Figs. 3(a) and 3(b).

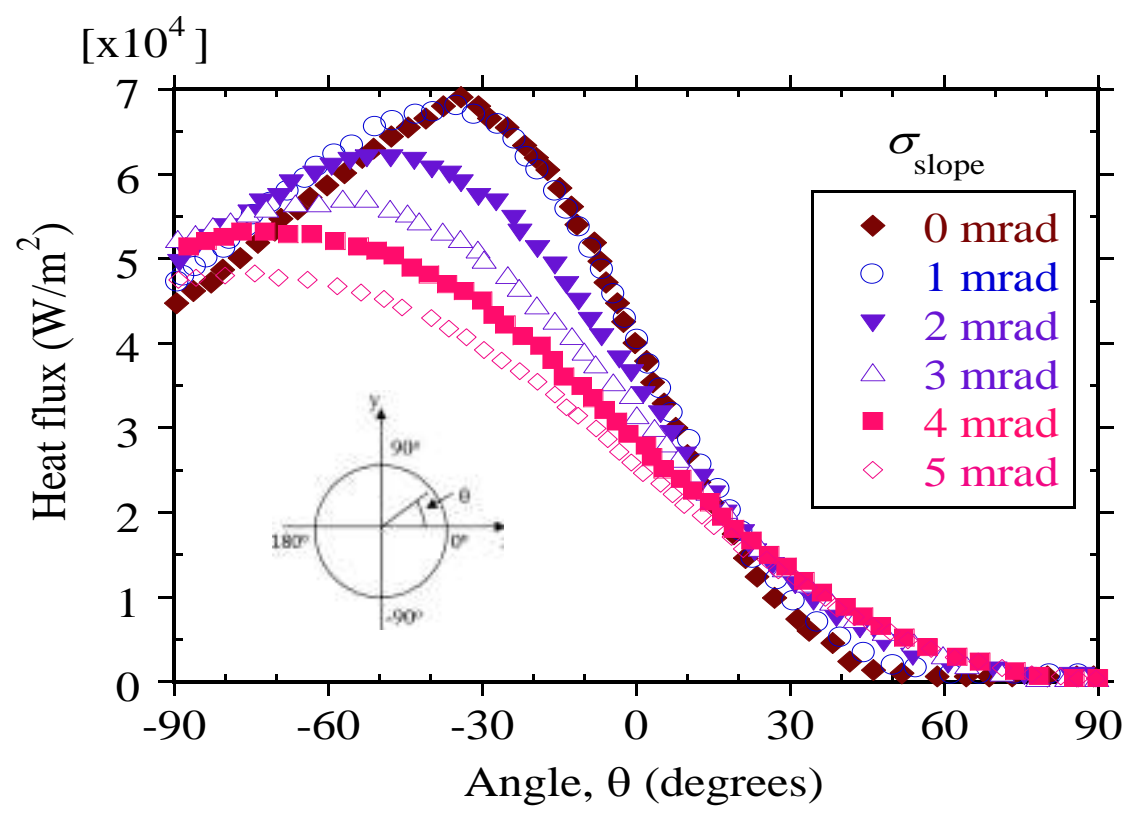

(a)

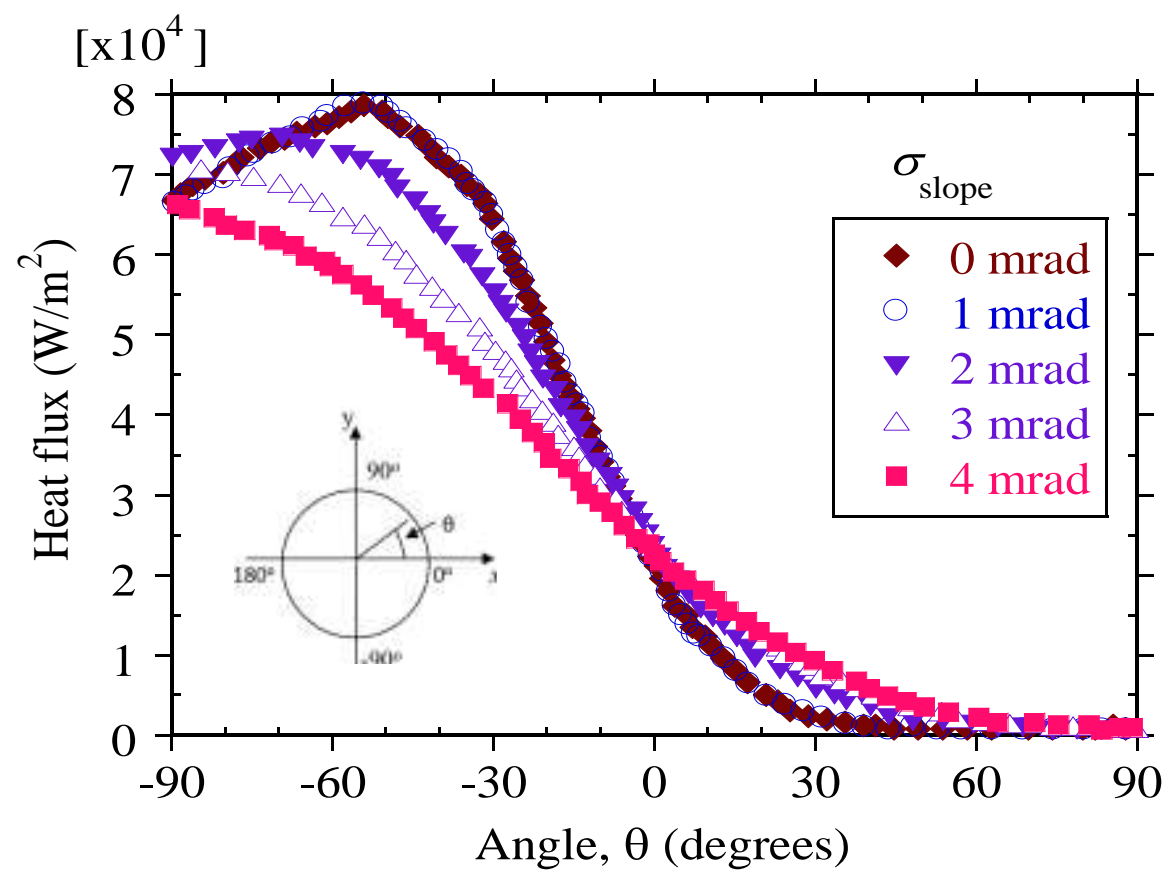

(b)

Fig.3. Absorber tube circumferential heat flux distribution for a parabolic trough collector with a rim angle of $80^{\circ}$ as a function of slope error, $\sigma_{\text {slope }}$ and receiver circumferential angle, $\theta$ (a) for a concentration ratio of 86 and a specularity error of $2 \mathrm{mrad}(\mathrm{b})$ for a concentration ratio of 113 and specularity error of $0.5 \mathrm{mrad}$. 


\subsection{Other flow and thermal boundary conditions}

The other boundary conditions used are similar to those in Mwesigye et al. [37], they are:

- A velocity inlet and pressure outlet at the absorber tube's inlet and outlet, respectively.

- No-slip and no-penetration for all receiver walls.

- Symmetry for the annulus space inlet and outlet. This is because there is no flow in the receiver's annulus space. With this, there are no normal gradients of flow variables.

- A symmetry boundary condition for the entire receiver due to the symmetrical nature of the received heat flux and of the flow inside the receiver.

- The heat transfer from the outer wall of the receiver was modelled using a mixed radiation and convection boundary condition. With this, the receiver is assumed to be surrounded by a large enclosure, the sky. The transfer of energy by radiation between the glass cover and the sky is given by the Stefan-Boltzmann law with the sky temperature given by [62]

$T_{s k y}=0.0552 T_{a m b}^{1.5}$

- Transfer of energy by convection heat transfer from the receiver to the surroundings was obtained by specifying a convection heat transfer coefficient as [63]

$h_{w}=V_{w}^{0.58} d_{g o}{ }^{-0.42}$

The wind speed $\left(V_{w}\right)$ is normal to the axis of the receiver, it was maintained at $2 \mathrm{~m} \mathrm{~s}^{-1}$ and the ambient temperature at $300 \mathrm{~K}$ for all cases.

For this study, the simulation parameters used, including collector geometrical parameters, environmental parameters, optical parameters and flow parameters are given in Table 1.

Table 1: Simulation parameters

\begin{tabular}{cccc}
\hline Parameter & Value & Parameter & Value \\
\hline$W_{a}$ & $9.0 \mathrm{~m}$ & $d_{r i}$ & $0.076 \mathrm{~m}$ \\
$L$ & $5.0 \mathrm{~m}$ & $d_{r o}$ & $0.08 \mathrm{~m}$ \\
$\rho$ & 0.97 & $d_{g i}$ & $0.120 \mathrm{~m}$ \\
$\alpha_{a b s}$ & 0.98 & $d_{g o}$ & $0.125 \mathrm{~m}$ \\
$\varphi_{r}$ & $80^{\circ}$ & $\tau_{g}$ & 0.96 \\
$C_{R}=W_{d} / d_{r o}$ & 113 & $\phi$ & $0-6 \%$ \\
$T_{\text {inlet }}$ & $350-650 \mathrm{~K}$ & $T_{a m b}$ & $300 \mathrm{~K}$ \\
$\operatorname{Re}$ & $3.56 \times 10^{3}-1.15 \times 10^{6}$ & $\varepsilon_{g}$ & 0.86 \\
$\sigma_{\text {slope }}$ & $3 \mathrm{mrad}$ & $\sigma_{\text {mirror }}$ & $0.5 \mathrm{mrad}$ \\
\hline
\end{tabular}


To accurately account for the thermal performance of the receiver, the emissivity of the receiver's absorber tube was taken to be temperature dependent. The receiver used in this study has characteristics of the PTR70 Schott's receiver. Therefore, the emissivity of the absorber tube coating was taken as given in Burkholder and Kutscher [10]

$\varepsilon_{r o}=0.062+2 \times 10^{-7} T_{r o}{ }^{2}$

In Eq. (30), $T_{r o}$ is the absorber tube temperature in degrees Celsius.

\section{Numerical modelling procedure and code validation}

\subsection{Solution procedure}

A numerical modelling approach was followed in this work to obtain the solution of the governing continuity, momentum and energy equations together with the boundary conditions. For this purpose, a commercial computational fluid dynamics tool ANSYS ${ }^{\circledR} 15.0$ was used [64]. The solution procedure involves modelling the geometry of the receiver in ANSYS design modeler, meshing the model in ANSYS Meshing and solving the governing equations together with the boundary conditions in ANSYS FLUENT [64], a computational fluid dynamics code based on the finite volume method.

The SIMPLE algorithm was used for pressure-velocity coupling [65]. Second-order upwind schemes were used for the integration of the boundary conditions, together with the computational domain. To ensure a fully converged solution, the monitors for all residuals were monitored until they ceased changing for more than 150 iterations. The solution was fully converged when the scaled residuals for the continuity equation were less than $10^{-4}$, the scaled residuals for momentum, turbulent kinetic energy and turbulent dissipation rate were less than $10^{-6}$ and less than $10^{-8}$ for energy. Moreover, the integral value of the entropy generation rate remained unchanged for more than 100 successive iterations with the above convergence criteria. Equations (12) and (13) were written as custom field functions to give the entropy generation rates in the post processing stage of the computational fluid dynamics analysis.

The entropy generation rate was used to test the dependence of the solution on the computational grid (mesh) used according to Eq. (31). The solution was taken to be mesh independent when the percentage change in the entropy generation rate remained lower than $1 \%$ as the mesh size was reduced. Similar to our previous study [37], a mesh size of $26 \%$ the 
absorber tube diameter in the flow direction and $3 \%$ of the absorber tube diameter in the tube's cross-section gave a mesh independent solution for all combinations of parameters used. The mesh used consisted of mainly hexahedral elements with a structured mesh (prism layers) in the absorber tube wall normal direction. The number of mesh elements was in the range 725,000 to 825,660 depending on the Reynolds number. High Reynolds numbers required very thin and more prism layers, thus a higher mesh count.

$\left|\frac{S_{g e n}{ }^{i}-S_{g e n}{ }^{i+1}}{S_{g e n}{ }^{i+1}}\right| \leq 0.01$

The indices $i$ and $i+1$ indicate the mesh before and after refinement respectively.

To capture the high resolutions of flow variables near the wall, in order to ensure a more precise heat transfer, fluid friction and entropy generation prediction, values of the dimensionless wall coordinate, $y^{+} \approx 1$ were used. Where $y^{+}=y u_{\tau} / v$, in which $v$ is the fluid's kinematic viscosity, $y$ is the distance from the wall, and $u_{\tau}$ is the friction velocity given by $u_{\tau}=\sqrt{\left(\tau_{w} / \rho\right)}$. With such low values of $y^{+}$, the enhanced wall treatment was used [64].

\subsection{Data reduction}

The following parameters were used to present the results of this study.

The Reynolds number is given by

$\operatorname{Re}=\rho_{n f} u_{m} d_{r i} / \mu_{n f}$.

Where $d_{r i}$ is the receiver's absorber tube inner diameter, $\rho_{n f}$ is the nanofluid density, $\mu_{n f}$ is the nanofluid viscosity and $u_{m}$ is the mean flow velocity.

The average heat transfer coefficient is given by

$h=q^{\prime \prime} /\left(T_{r i}-T_{b u l k}\right)$

Where $T_{r i}$ is the average absorber tube inner wall temperature and $T_{b u l k}$ is the heat transfer fluid bulk temperature given by $\left(T_{\text {inlet }}+T_{\text {outlet }}\right) / 2$.

The average Nusselt number is given by 


$$
N u=h d_{r i} / \lambda_{n f}
$$

Where $\lambda_{n f}$ is the thermal conductivity of the fluid.

The Darcy-Weisbach friction factor is defined as

$$
f=\frac{\Delta P}{\frac{1}{2} \rho_{n f} \cdot u_{m}^{2} \cdot \frac{L}{d_{r i}}}
$$

To validate the results from the numerical model, several correlations and data available in literature were used. For friction factors in smooth tubes, the correlations used include the Petukhov's correlation [66], given as

$$
f=(0.790 \ln \mathrm{Re}-1.64)^{-2}
$$

Another friction factor correlation obtained from Mwesigye et al. [16] was used. This is given by

$$
f=0.173 \mathrm{Re}^{-0.1974}
$$

For Nusselt numbers, the Gnielinski's correlation for both low and high Reynolds numbers [66], given by

$$
N u=\frac{(f / 8)(\operatorname{Re}-1000) P r}{1+12.7(f / 8)^{0.5}\left(\operatorname{Pr}^{2 / 3}-1\right)}
$$

For $0.5 \leq \operatorname{Pr} \leq 2000$ and $3 \times 10^{3} \leq \operatorname{Re} \leq 5 \times 10^{6}$

From Mwesigye et al. [16], a Nusselt number correlation was derived which is given as

$$
N u=0.0104 \operatorname{Pr}^{0.374} \operatorname{Re}^{0.885}
$$

For heat transfer enhancement with nanofluids, the Pak and Cho [67] correlation obtained from experimental data was used. It is given by

$$
N u=0.021 \operatorname{Re}^{0.8} \operatorname{Pr}^{0.5}
$$


Equation (40) was derived for volume concentrations in the range 0-3\%, Reynolds numbers in the range $10^{4}-10^{5}$ and Prandtl numbers ranging from $6.54-12.33$ [67]. It was shown in Mwesigye et al. [37] that for high Reynolds numbers, significant deviations occur. A correlation for heat transfer performance for such high values of Reynolds numbers was suggested as [37]

$$
N u=0.008905 \operatorname{Re}^{0.8966} \operatorname{Pr}^{0.3805} \tilde{\phi}^{-1.1836 \times 10^{-3}}
$$

In which, the volume fraction was non-dimensionlised as $\tilde{\phi}=\phi / \phi_{\text {ref }}$, with $\phi_{\text {ref }}=1 \%$. The correlation in Eq. (41) predicted the Nusselt number within $\pm 4 \%$ for $\mathrm{Al}_{2} \mathrm{O}_{3}$ Syltherm 800 nanofluid. The correlation was obtained for $3560 \leq \operatorname{Re} \leq 1151000,0 \leq \phi \leq 8 \%, 350 \leq T_{\text {inlet }}$ $\leq 600 \mathrm{~K}$ and $9.27 \leq \operatorname{Pr} \leq 96.58$.

The fluid friction resulting from the flow of $\mathrm{Cu}$-Therminol ${ }^{\circledR} \mathrm{VP}-1$ nanofluid was compared with Eq. (42) obtained previously by Mwesigye et al. [37] for the same range of parameters as used in the derivation of Eq. (41).

$f=0.2085 \operatorname{Re}^{-0.2132} \tilde{\phi}^{1.0538 \times 10^{-2}}$

For local determination of entropy generation rates, equations presented in Section 3.2 were used. The local entropy generation rates were then integrated over the entire computational domain according to Eq. (14), to obtain the entropy generation rate for the entire computational domain. The volume integral of the entropy generation rate is available in the post processing stage of the computational fluid dynamics analysis.

\subsection{Validation of numerical results}

The results of this study have been validated with correlations and data available in literature. First, the heat transfer performance was validated using the Gnielinski correlation [66] given by Eq. (38) and a correlation by Mwesigye et al. [16] given by Eq. (39). Good agreement was achieved for the entire range of inlet temperatures used in this study as shown in the scatter plot in Fig. 4. The fluid friction from the present study was validated with the friction factor correlations by Petukhov [66] given by Eq. (36) and a correlation from Mwesigye et al. [16], given by Eq. (37). Excellent agreement was obtained, as shown in Fig. 4. In this figure 


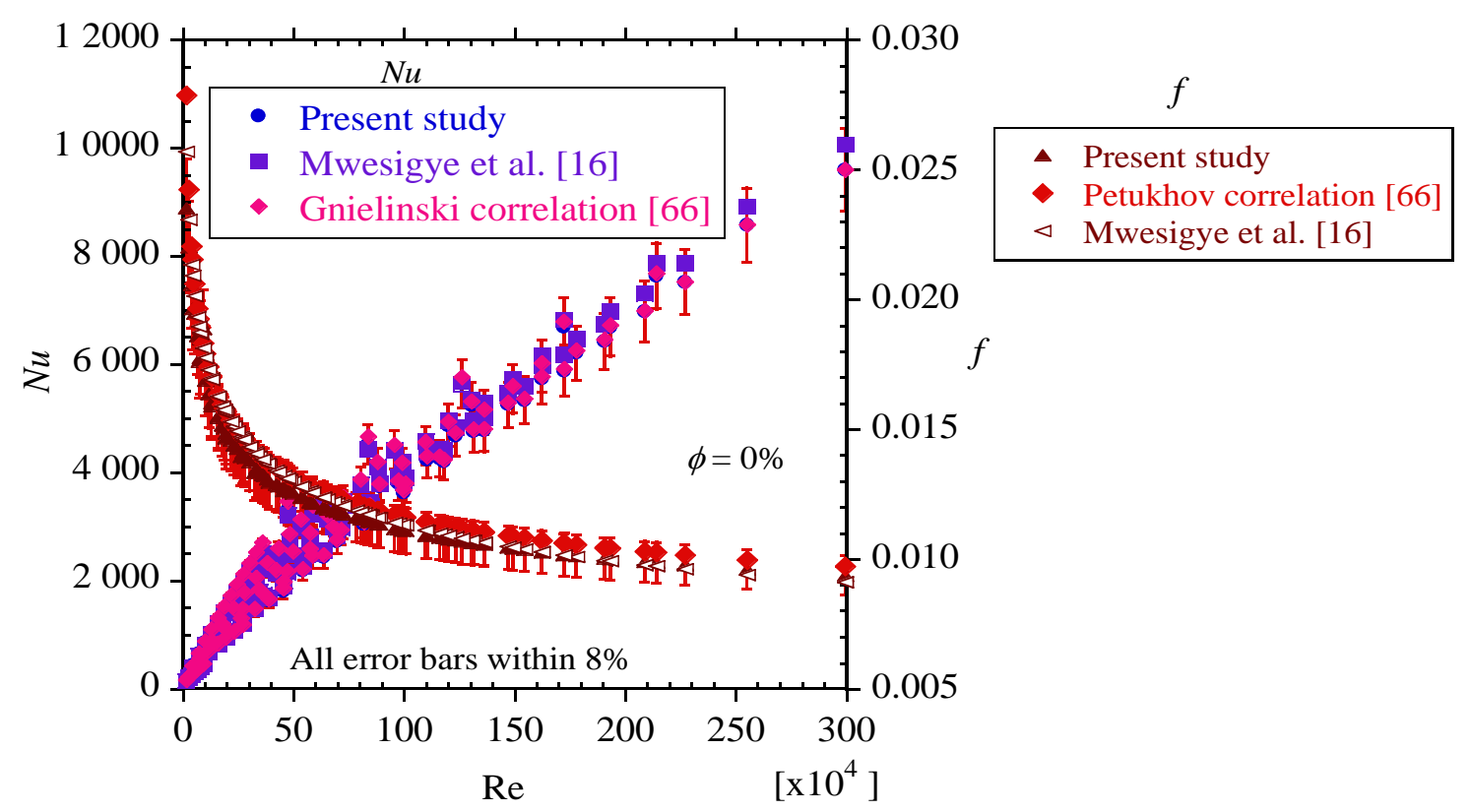

Fig. 4. Validation of receiver heat transfer and fluid friction performance for the case of $\phi=0 \%$.

and in Figs. 5 and 7, the error bars are plotted on present study data points to show the deviation of the present study results from the results available in literature.

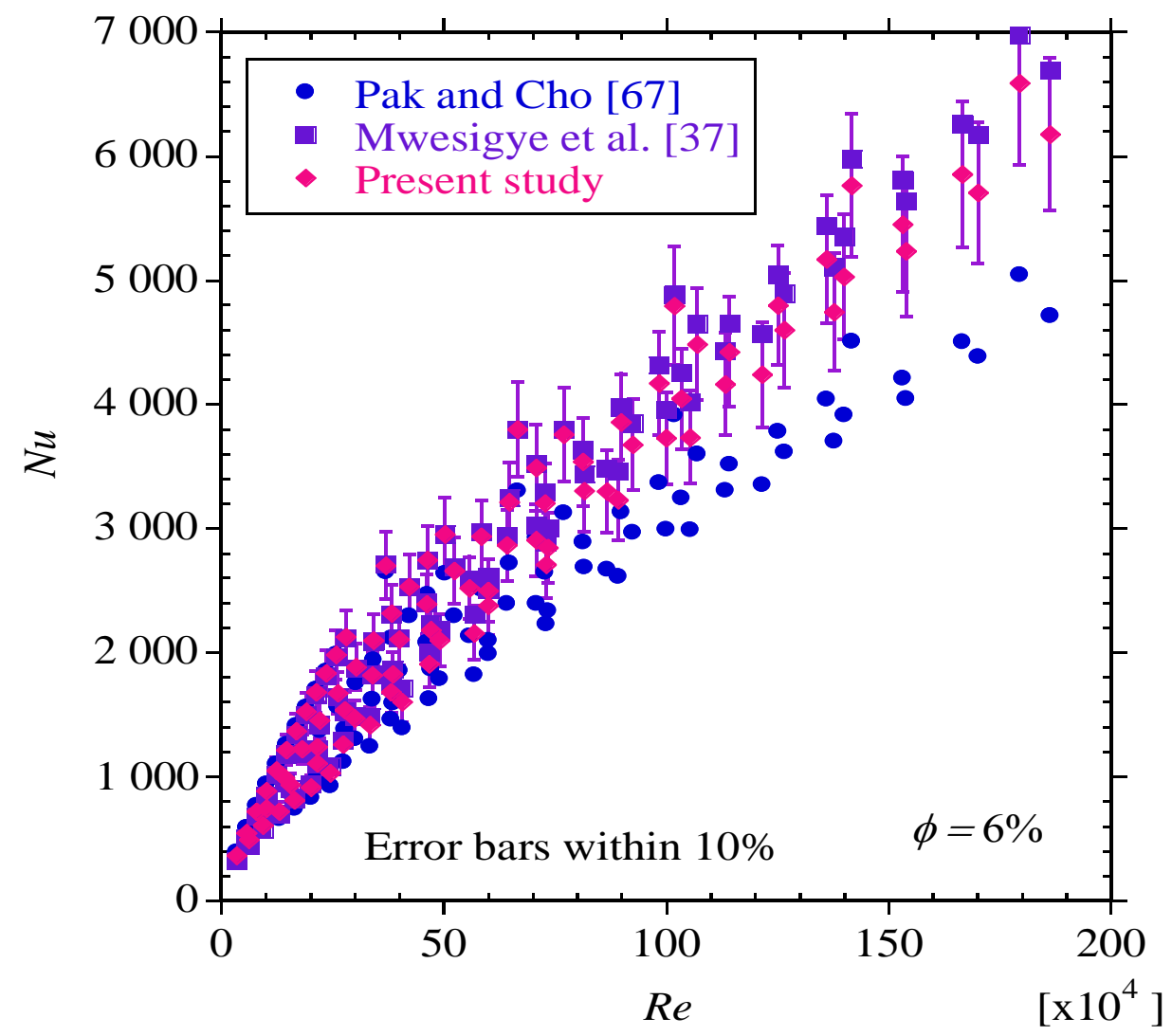

Fig. 5. Comparison of present study Nusselt number with literature for $\phi=6 \%$.

With the nanofluid models used, the Nusselt number correlations by Pak and Cho [67] and Mwesigye et al. [37] in Eqs. (40) and (41) respectively, were compared with present study results. The Pak and Cho [67] correlation predicts the Nusselt number well within the range 
of parameters for which it was derived. At higher Reynolds numbers, deviations as high as $30 \%$ exist. The correlation by Mwesigye et al. [37] predicts the heat transfer performance within $7 \%$ for about $95 \%$ of the data as shown in Fig. 5 for a volume fraction of $6 \%$, similar scatter plots can be obtained at other values of volume fraction. Results of fluid friction from this study are within $6 \%$ of the values predicted by Eq. (42) as shown in Fig. 6 at a volume fraction of $4 \%$.

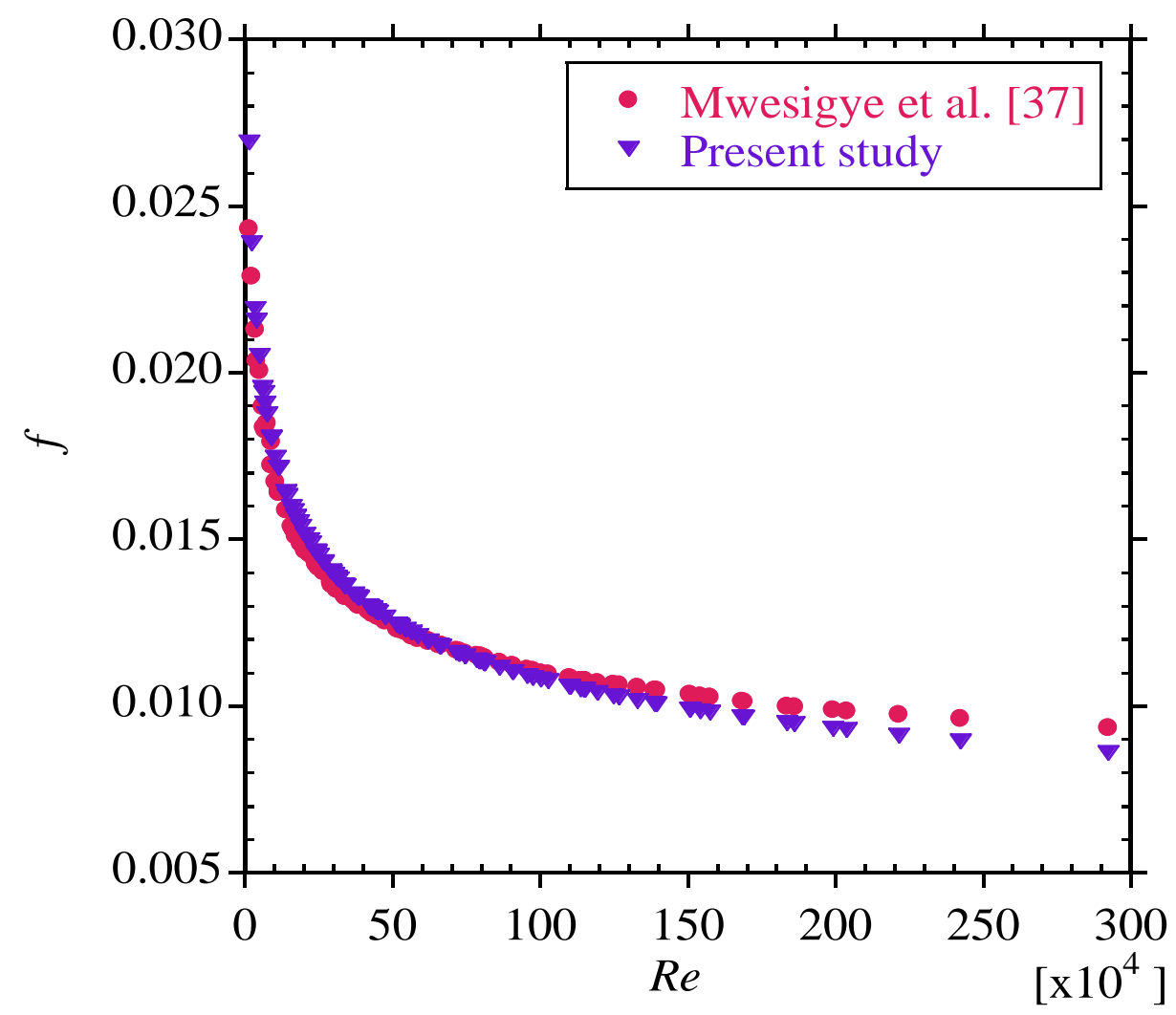

Fig. 6. Comparison of present study friction factor with literature for $\phi=4 \%$.

To have confidence in the receiver thermal model, the thermal efficiency values of this study were compared with those obtained in experimental investigations by Dudley et al. [68] as shown in Fig. 7. As shown, good agreement was achieved and the accuracy of the present model is significantly better than that obtained in a previous study where a non-realistic heat flux profile was used [69]. In this comparison, similar experimental conditions used by Dudley et al. [68] and a realistic heat flux profile were used in the numerical analysis, a SEGS LS-2 receiver was also used similar to the receiver in the experiments. After validating the receiver thermal model, the material properties of the receiver were switched to those of the Schott's PTR70 receiver used in this study. For the Schott's PTR70 receiver, the receiver thermal loss was compared with heat loss curves given by Dreyer et al. [70]. As shown in Fig. 8, the receiver thermal model compares excellently with experimental results of Dreyer et al. [70] for a receiver with an emissivity of $11.4 \%$ or 0.114 at $400{ }^{\circ} \mathrm{C}(\mathrm{e} 400=11.4 \%)$. The 


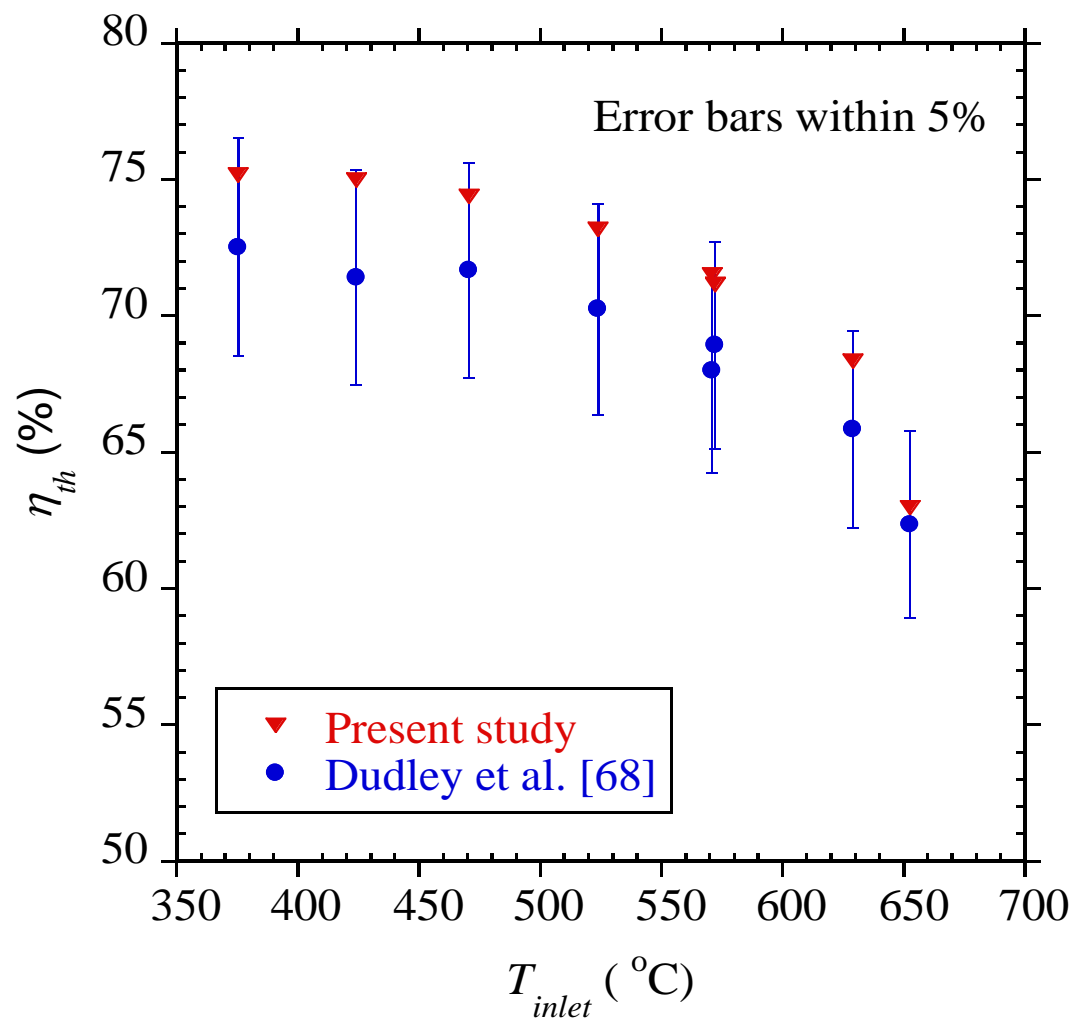

Fig. 7. Comparison of present study thermal efficiency with experimental results from Sandia National Laboratories by Dudley et al. [68].

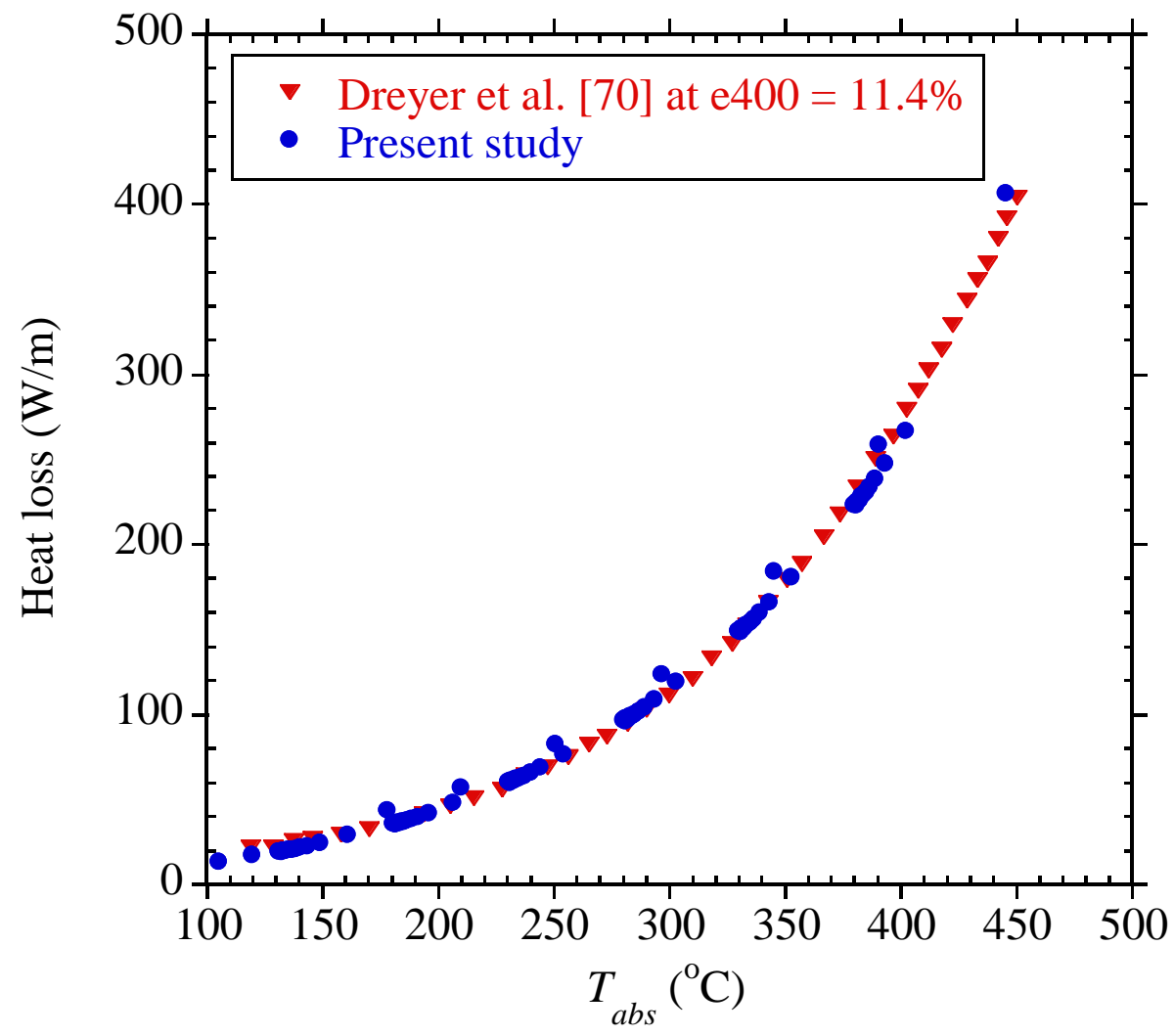

Fig.8. Comparison of current study receiver thermal model with experimental measurements by Dreyer et al. 
entropy generation model compares well with the analytical results of the Bejan expression [47], given by Eq. (15). The validation of the entropy generation model was given in earlier studies $[69,71]$.

\section{Results and discussions}

\subsection{Receiver temperature distribution}

Following the non-uniform heat flux distribution on the receiver's absorber tube, the receiver's circumferential temperature distribution is expected to be non-uniform. Fig. 9, shows the temperature distribution in the receiver at an inlet temperature of $600 \mathrm{~K}$, a flow

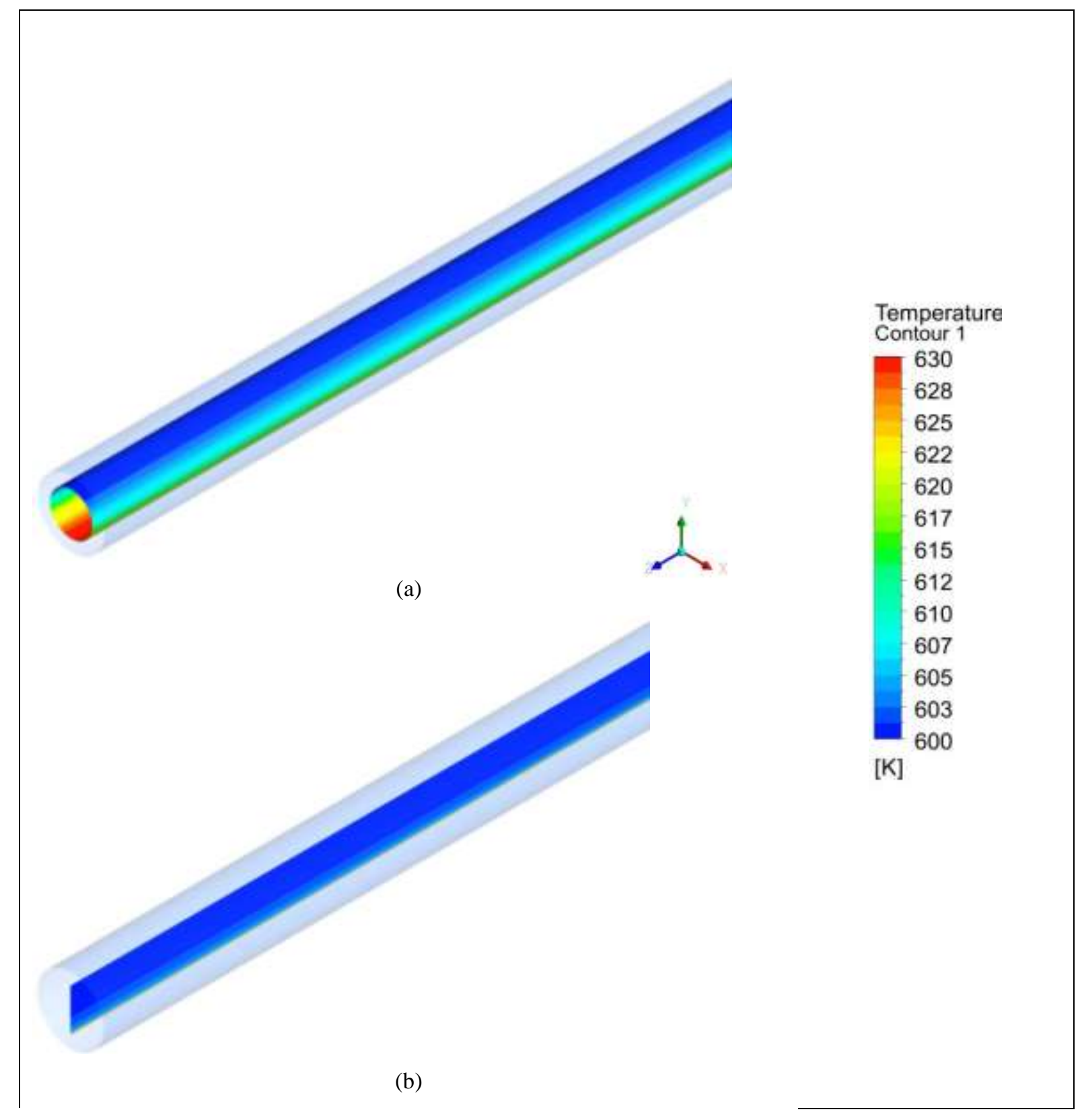




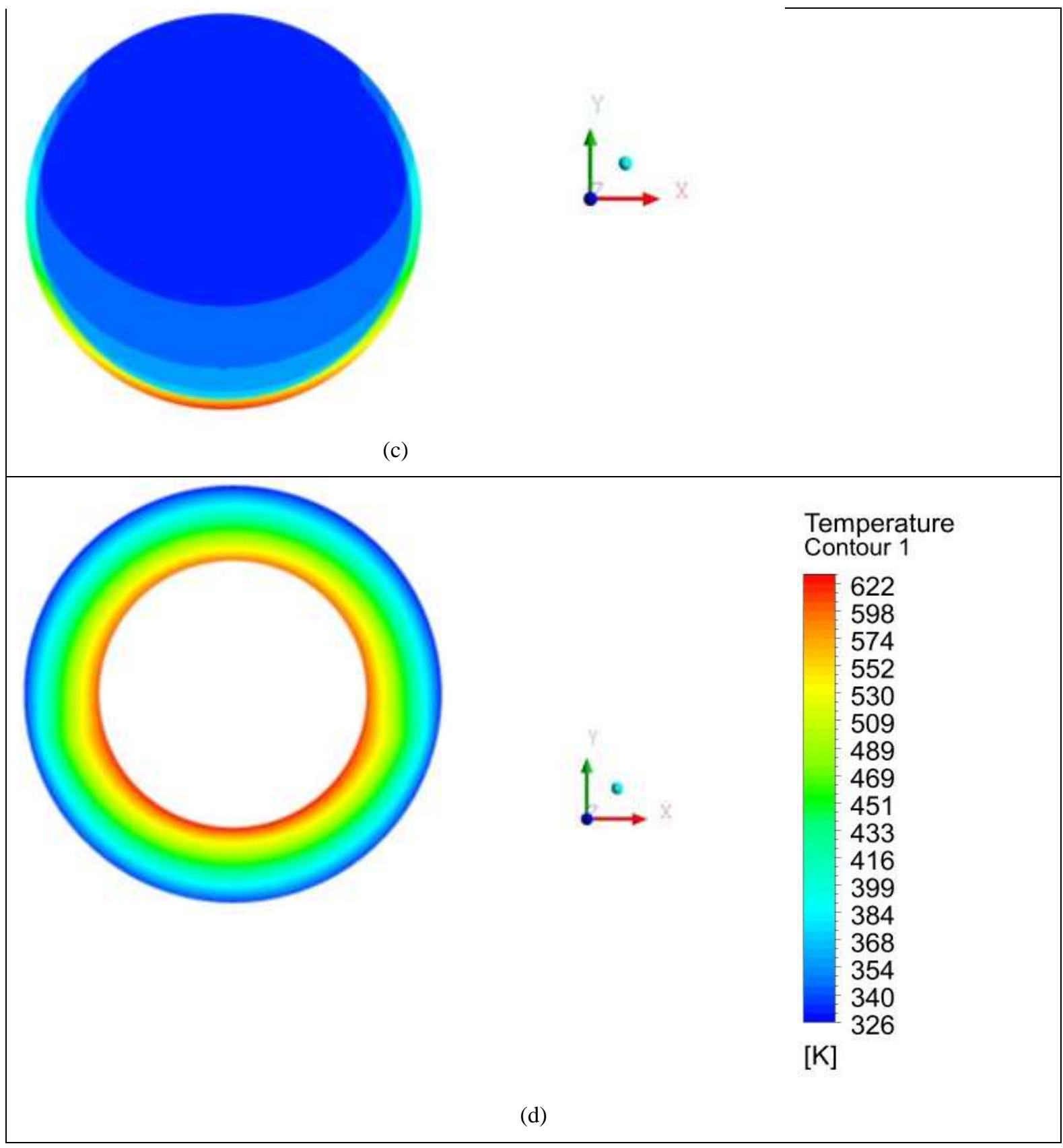

Fig. 9. Contours showing receiver temperature distribution for a parabolic trough system with $C_{R}=113, \varphi_{r}=80^{\circ}$ $\sigma_{\text {slope }}=3 \mathrm{mrad}, \sigma_{\text {mirror }}=0.5 \mathrm{mrad}$, an inlet temperature of $600 \mathrm{~K}$ at a flow rate of $36.8 \mathrm{~m}^{3} \mathrm{~h}^{-1}$ (a) lateral view of the receiver's absorber tube outer wall (b) lateral view of the symmetry plane showing the heat transfer fluid and the absorber tube, (c) cross-section view of the absorber tube outlet, and (d) cross-section view of the receiver's annulus space.

rate of $36.8 \mathrm{~m}^{3} \mathrm{~h}^{-1}$ and a volume fraction of $0 \%$ for the considered system with a rim angle of $80^{\circ}$, geometrical concentration ratio of 113 , slope error of $3 \mathrm{mrad}$ and specularity error of 0.5 mrad. From the figure, the non-uniformity of the temperature in the receiver's circumference is clearly shown. This is a result of the non-uniformity of the heat flux incident on the receiver's absorber tube. The absorber tube circumferential temperature difference is about 
$30 \mathrm{~K}$ at a flow rate of $36.8 \mathrm{~m}^{3} \mathrm{~h}^{-1}$. The circumferential temperature difference is higher at lower flow rates and reduces as the flow rates increase.

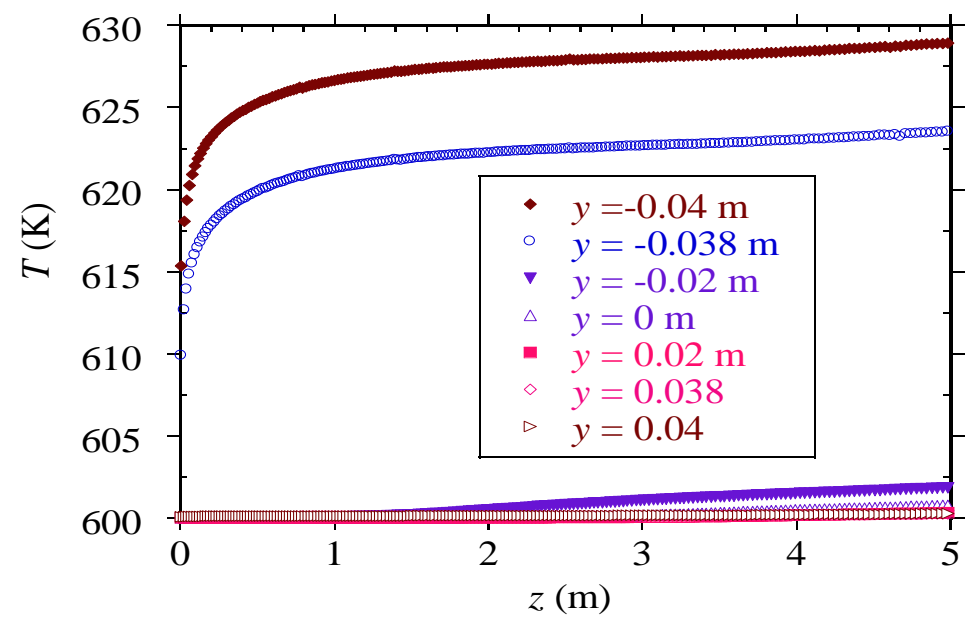

(a)

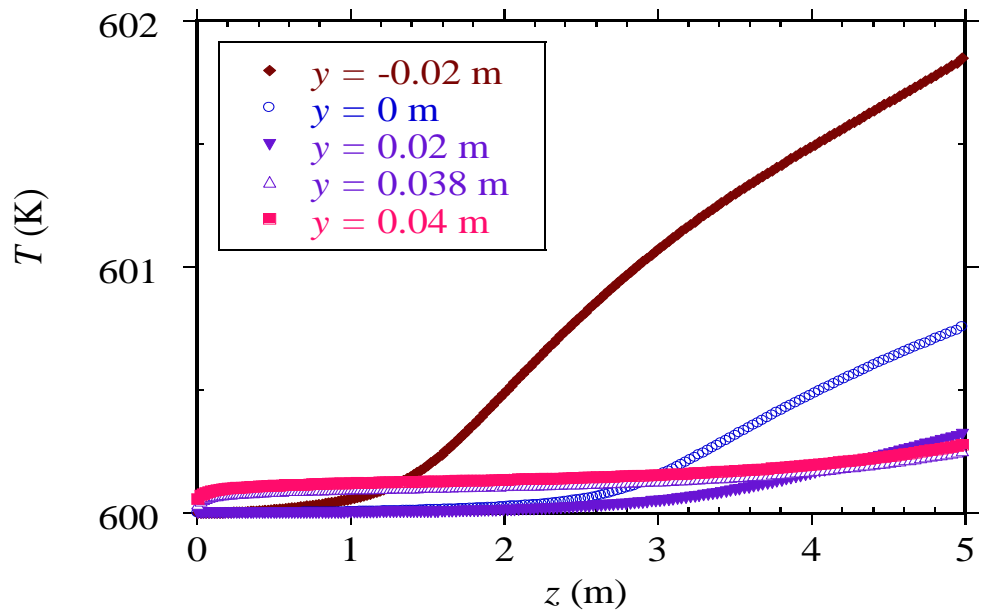

(b)

Fig. 10. Variation of temperature along the tube length at different values of $y$ on the symmetry plane.

Due to the fact that the lower half of the absorber tube has a much higher heat flux compared to the upper half, it is expected that at different locations along the length of the tube, the temperature is different. The variation of temperature along the receiver tube length is shown in Fig. 10 at different values of $y$ on the receiver symmetry plane. Where, $y=0 \mathrm{~m}$ is the centreline of the absorber tube, $y=0.04 \mathrm{~m}$ is the top most part of the absorber tube (absorber tube outer wall), $y=0.038 \mathrm{~m}$ is the top most part of the absorber tube inner wall, $y=-0.04 \mathrm{~m}$ is the bottom most part of the absorber tube outer wall and $y=-0.038 \mathrm{~m}$ is the bottom most part of the absorber tube inner wall. As shown, the temperature increases along the length of the receiver from the inlet to the outlet as the heat transfer fluid gains heat from the heated absorber tube. The temperature also decreases with increasing values of $y$ since the absorber tube heat flux is higher on the lower half and lower on the upper half of the tube. A closer look at the values of $y$ far from the heated lower half) of the tube $(y \geq-0.02 \mathrm{~m})$ shows that 
significant increase in temperature occurs at different values of $z$ for each $y$ value. Increase in temperature for locations closer to the lower heated half of the tube start at lower values of $z$ and have significantly higher temperatures compared to those far from the heated lower half of the tube.

\subsection{Heat transfer performance}

Heat transfer coefficients have been used to compare the heat transfer performance of a receiver with nanofluids to that without nanofluids. As shown in Figs 11 (a)-11(c), the heat transfer performance increases as the nanoparticle volume fraction increases and as the Reynolds numbers increase. The trend is the same for all temperatures as shown in sample variations at the temperatures of $400 \mathrm{~K}, 500 \mathrm{~K}$ and $600 \mathrm{~K}$. It can also be noted from the figures that significant improvements in heat transfer performance occur as nanoparticle volume fractions increase above $2 \%$. The improvement in heat transfer performance can be attributed to the improved thermal properties of the base fluid with the suspension of nanoparticles. As expected, a thinner boundary layer at higher Reynolds numbers, lower absorber tube temperatures and faster heat removal rates makes the heat transfer coefficient higher. Thus, the heat transfer coefficient also increases as the Reynolds number increases.

As shown in the figures, high heat transfer coefficients exist at high inlet temperatures despite the fact that the lowest Reynolds numbers and highest Reynolds numbers correspond to the same flow rates of $1.22 \mathrm{~m}^{3} \mathrm{~h}^{-1}$ and $135 \mathrm{~m}^{3} \mathrm{~h}^{-1}$, respectively at each inlet temperature considered. This is due to the variation of heat transfer fluid properties with temperatures according to Eqs. (16)-(20). The density, viscosity and thermal conductivity of the heat transfer fluid reduce as temperatures increase while the specific heat capacity increases with increasing in temperatures. Thus, for the same flow rate, the Reynolds number increases as the temperature increases, thereby leading to higher heat transfer performance. For the range of parameters considered in this study, the heat transfer performance increases by $8 \%, 18 \%$ and $32 \%$ as the nanoparticle volume fraction in the base fluid increases to $2 \%, 4 \%$ and $6 \%$, respectively. 


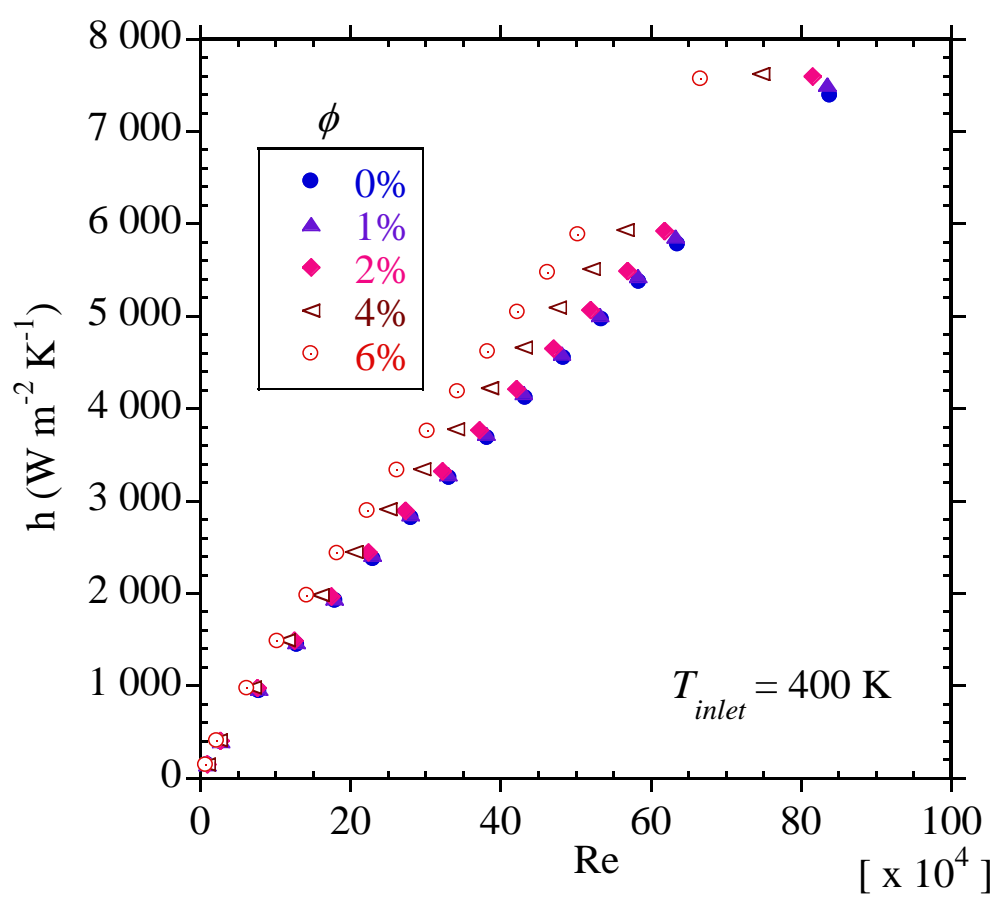

(a)

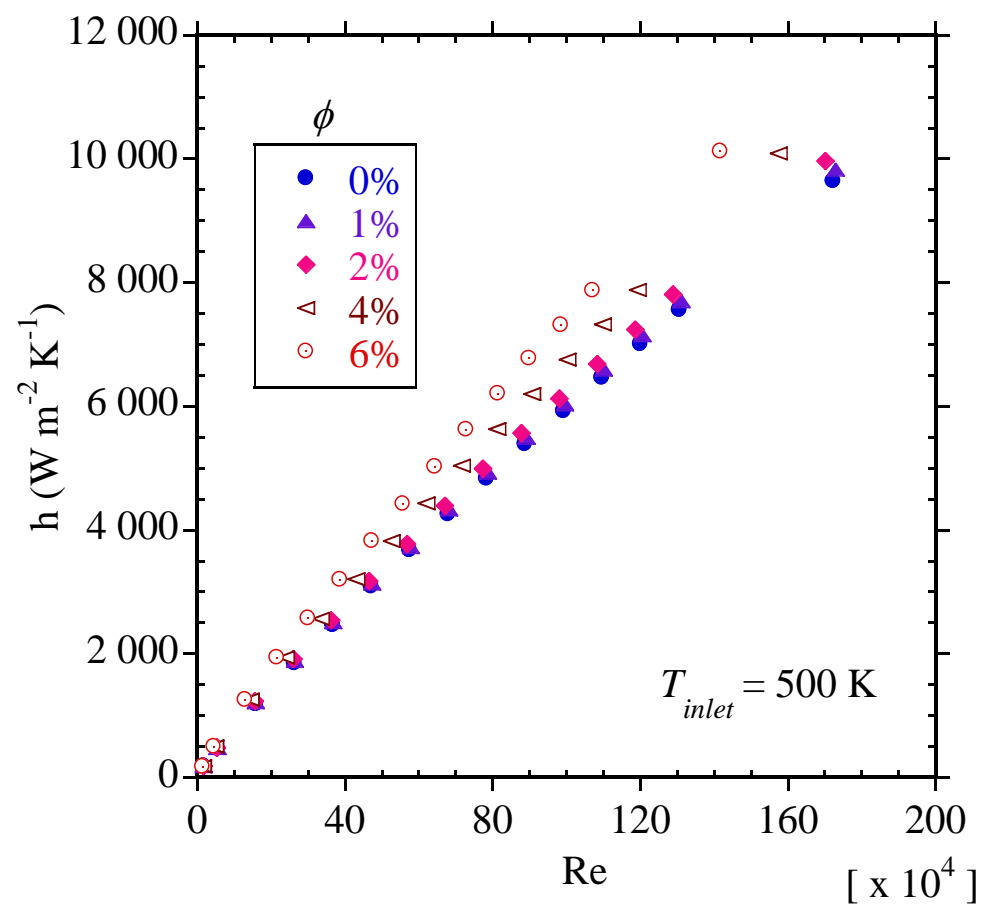

(b) 


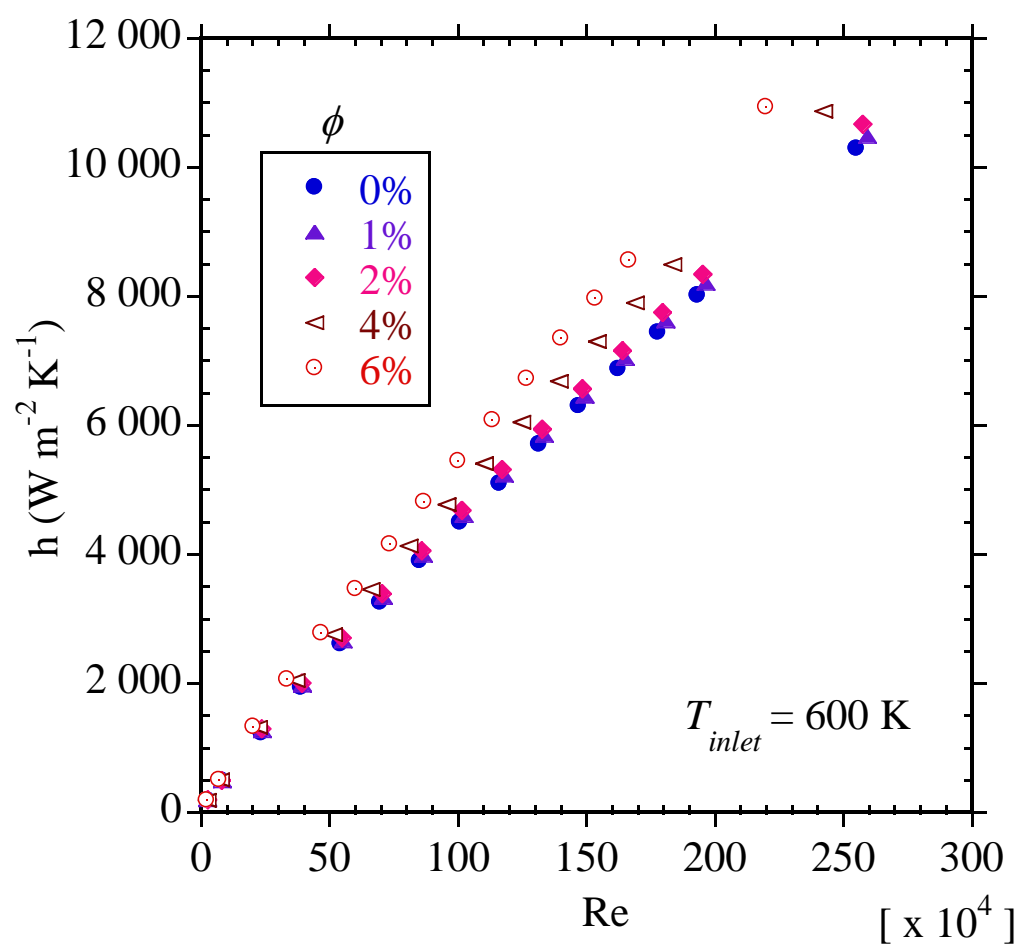

(c)

Fig. 11. Heat transfer performance as a function of Reynolds number and nanoparticle volume fraction. (a) 400 $\mathrm{K}$, (b) $500 \mathrm{~K}$ and (c) $600 \mathrm{~K}$.

\subsection{Pressure drop}

As shown in Fig. 12, the inclusion of nanoparticles in the base fluid leads to a significant increase in the pressure drop thus requiring more pumping power. This expected since the density and viscosity of the nanofluid are higher than those of only the base fluid. The pressure drop reduces as the temperatures increase owing to the temperature dependent properties used. The density and viscosity of the base fluid and thus of the nanofluid reduce as the temperatures increase. Thus, as shown in Fig. 12(a) and 12(b), at the same flow rates, say the one that gives the highest Reynolds number, $135 \mathrm{~m}^{3} \mathrm{~h}^{-1}$, the pressure drop is $7734 \mathrm{~Pa}$ $\mathrm{m}^{-1}$ at $400 \mathrm{~K}$ and $5569 \mathrm{~Pa} \mathrm{~m}^{-1}$ at $600 \mathrm{~K}$ when the volume fraction is $6 \%$ and $6714 \mathrm{~Pa} \mathrm{~m}^{-1}$ at $400 \mathrm{~K}$ and $4796 \mathrm{~Pa} \mathrm{~m}^{-1}$ at $600 \mathrm{~K}$ when the volume fraction is $4 \%$. The pressure drop increases significantly at higher Reynolds numbers, this is expected since the flow becomes highly turbulent and thus higher pumping power is necessary. Given this variation of the heat transfer performance and the pressure drop with nanofluids, it becomes necessary to define another parameter to assess the thermal performance of the receiver, such that a trade-off between heat transfer performance and fluid friction can be arrived at. In the next section, thermal efficiency that combines heat transfer performance and pumping power is used. 


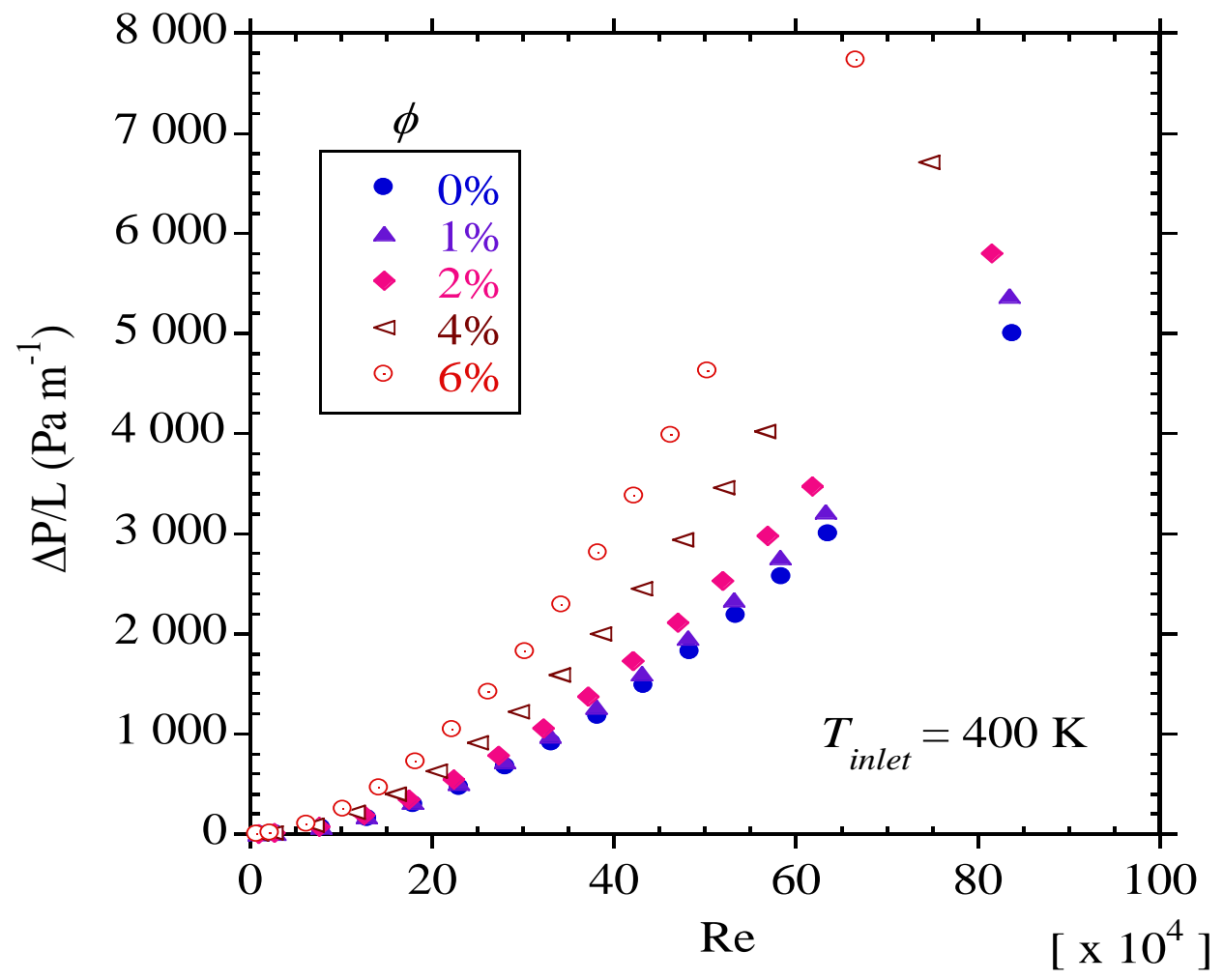

(a)

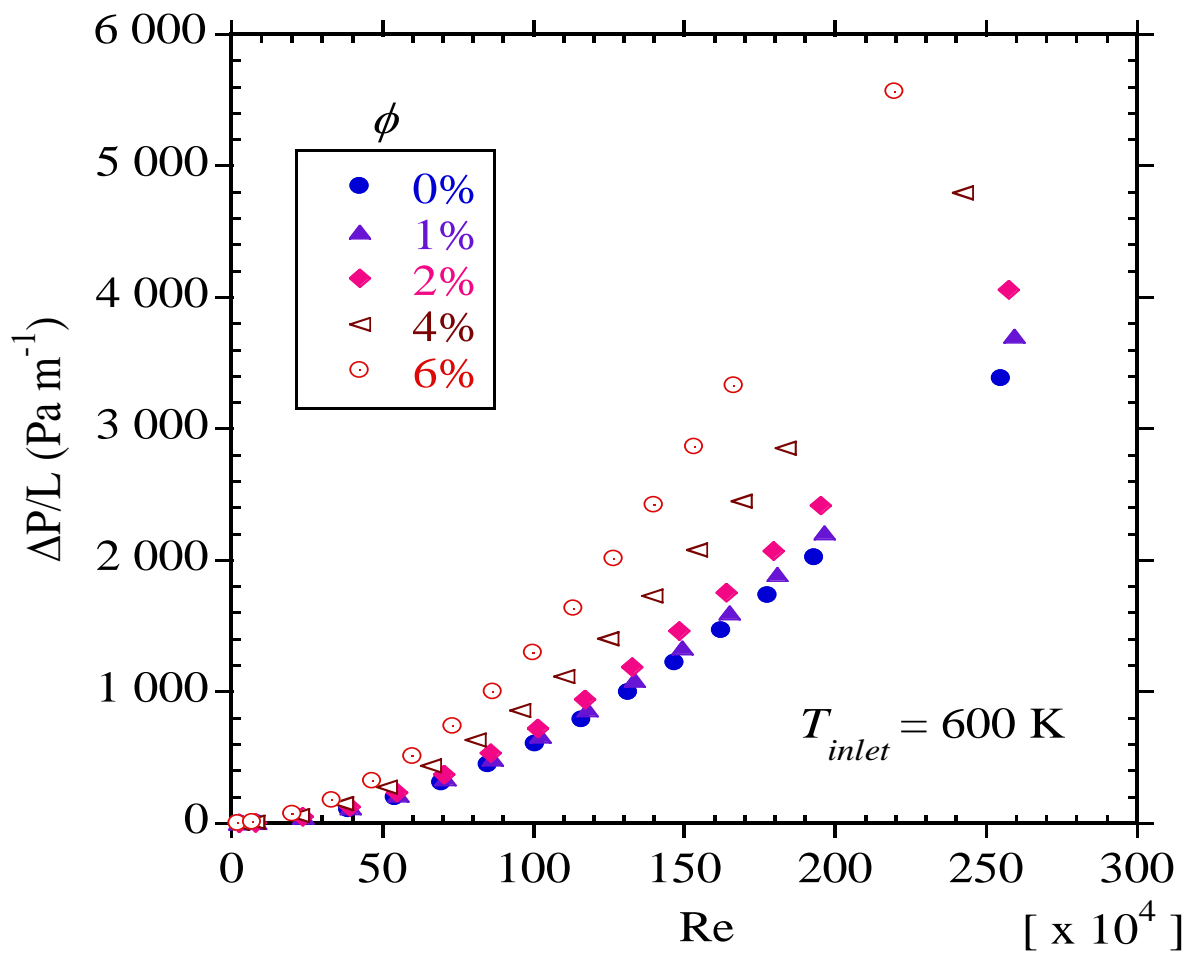

(b)

Fig.12. Pressure drop as a function of Reynolds number and nanoparticle volume fraction. (a) $400 \mathrm{~K}$, and (b) $600 \mathrm{~K}$. 


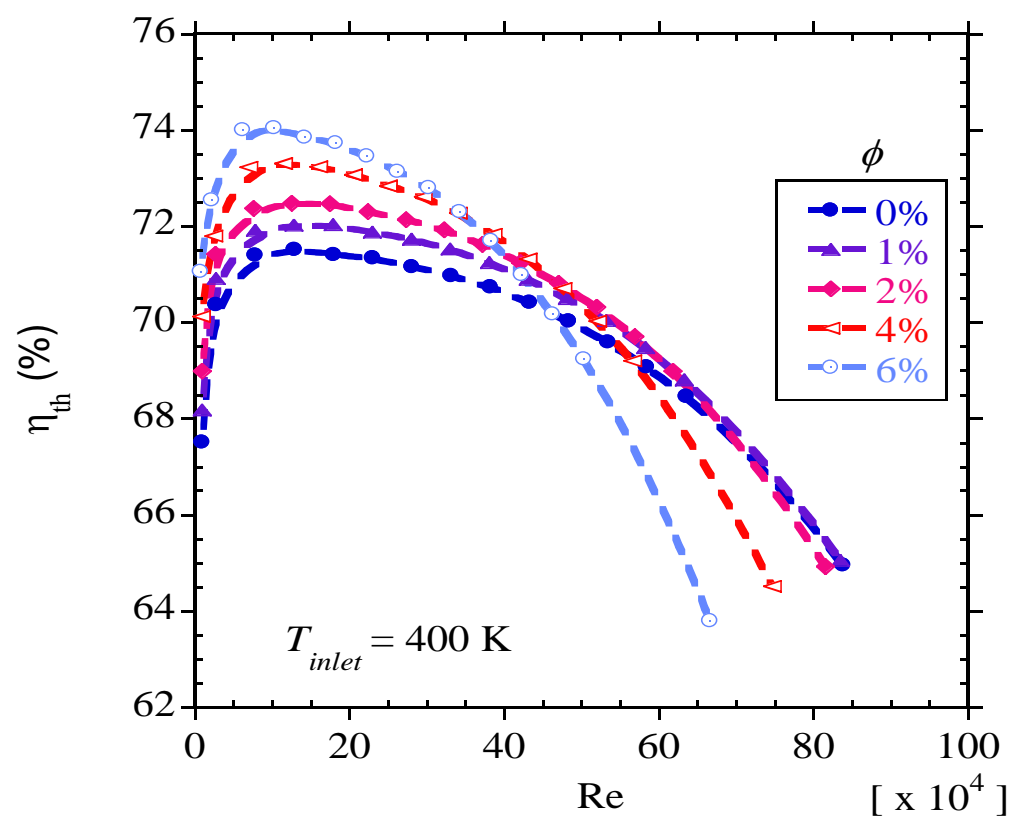

(a)

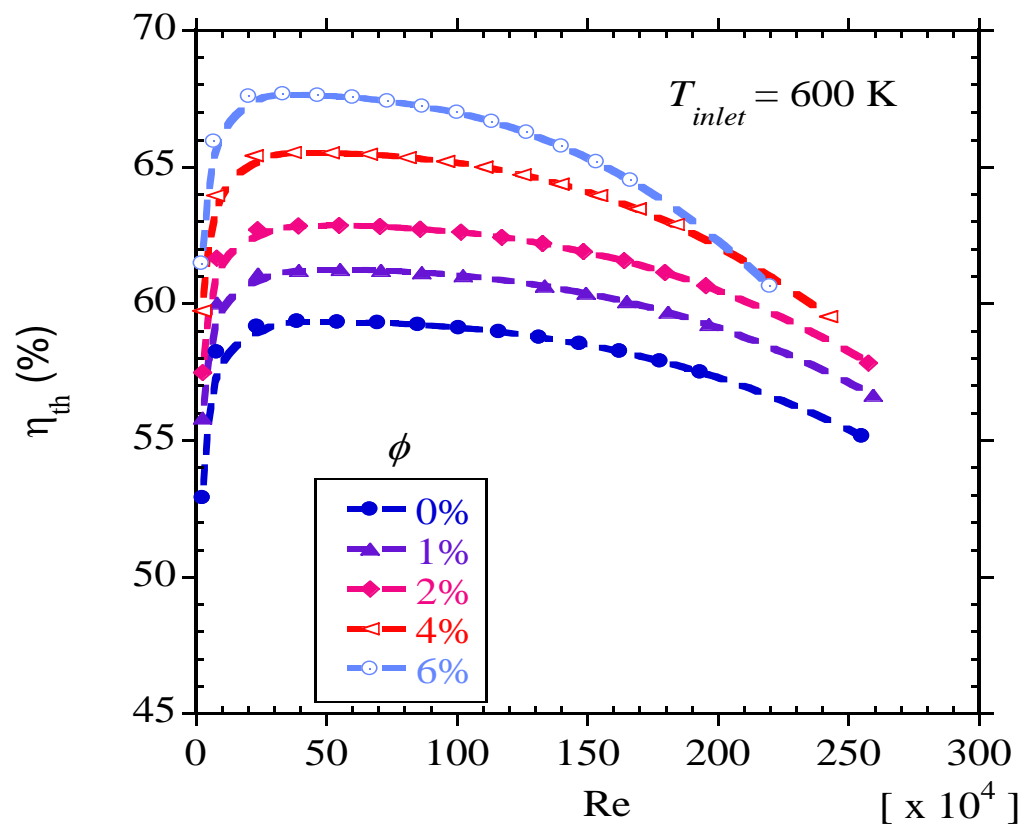

(b)

Fig. 13. Thermal efficiency as a function of Reynolds number and nanoparticle volume fraction. (a) $400 \mathrm{~K}$, and (b) $600 \mathrm{~K}$.

\subsection{Thermal efficiency}

As shown in sections 6.2 and 6.3, the increase in heat transfer performance as nanoparticle volume fraction increases is accompanied by an increase in pressure drop. The increase in pressure drop is much more pronounced at high Reynolds numbers and is much larger than the increase in heat transfer performance. To incorporate this increase in pressure drop in the performance assessment, Wirtz et al. [72] suggested an expression for thermal efficiency that considers both the increase in thermal performance as well as the effect of pumping power as: 
$\eta_{t h}=\frac{\dot{q}_{u}-\dot{W}_{p} / \eta_{e l}}{I_{b} A_{c}}$

In Eq. (43), the electrical efficiency, $\eta_{e l}$ is introduced to convert the pumping power to the same form as the useful heat energy. The electrical efficiency of the power block $\eta_{e l}$ used in Eq. (43) was taken as 32.7\% [72], $\dot{q}_{u}=\dot{m} c_{p}\left(T_{\text {outlet }}-T_{\text {inlet }}\right)$ and $\dot{W}_{p}=\dot{V} \Delta P$. Figures 13(a) and 13(c) show the thermal efficiency obtained using Eq. (43) as a function of the Reynolds number and the nanoparticle volume fraction at inlet temperatures of $400 \mathrm{~K}$ and $600 \mathrm{~K}$, respectively. The thermal efficiency is shown to increase as the nanoparticle volume fraction increases especially at low Reynolds numbers. The efficiency also increases with the Reynolds number, attains a maximum and begins to reduce as Reynolds numbers increase further at any given value of nanoparticle volume fraction. This trend is because the pumping power increases with Reynolds number and nanoparticle volume fraction and at some point becomes higher than the gain in thermal performance.

It can be seen from the figures that higher increase in thermal efficiency occur at high values of inlet temperatures. This is probably because, with the high concentration ratio used, high absorber tube temperatures will result and since the emissivity and thus receiver thermal loss increases with temperature, any reduction in absorber tube temperature due to heat transfer enhancement will lead to increased thermal performance. It can also be deduced from the figures that the thermal efficiency reduces and becomes lower than that in a tube using only the base fluid at lower flow rates for lower inlet temperatures and at higher flow rates as the inlet temperatures increase. This is likely due to the fact that at a given flow rate, the density and the viscosity of the heat transfer fluid reduce as temperatures increase and thus less pumping power requirements compared to when temperatures are low. As such, at high temperatures, there is a significant increase in receiver thermal performance and less pumping power requirements, thus higher increments in receiver thermal efficiency. However, the thermal efficiencies are lower in magnitude at higher temperatures given that the receiver thermal loss is much higher at higher temperatures than at low temperatures. The average absorber tube temperatures are shown in Figs. 14(a) and 14(b). The figures depict higher absorber tube temperatures at higher inlet temperatures. A slight reduction in the absorber tube temperatures as volume fraction increases can also be seen. Higher reductions in the absorber tube temperature as the nanofluid volume fraction increases exist at low flow rates. 


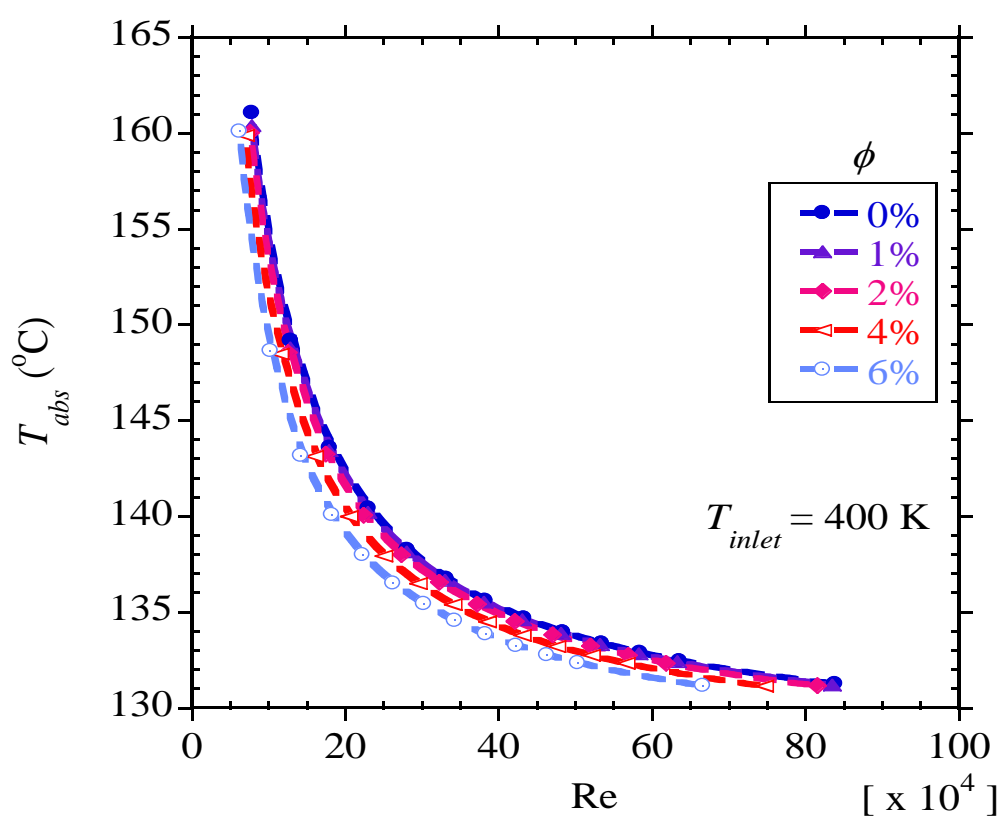

(a)

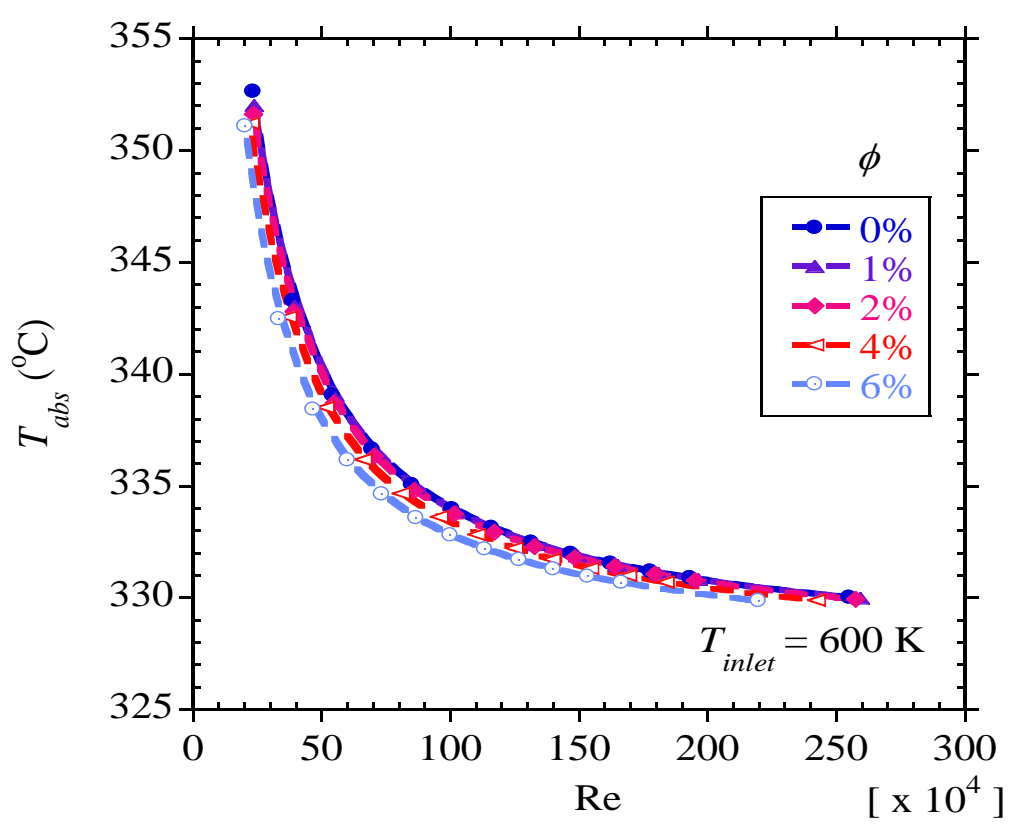

(b)

Fig. 14. Average absorber tube temperature as a function of Reynolds number and nanoparticle volume fraction (a) $T_{\text {inlet }}=400 \mathrm{~K}$, and (b) $T_{\text {inlet }}=600 \mathrm{~K}$.

With the use of nanofluids, the thermal efficiency increases up to $12.5 \%$. The highest increase is at the highest temperature of $650 \mathrm{~K}$ and nanofluid volume fraction of $6 \%$. 


\subsection{Entropy generation and thermodynamic analysis}

\subsubsection{Heat transfer and fluid friction irreversibilities}

The entropy generation due to convective heat transfer in the receiver's absorber tube generally has two parts: the heat transfer irreversibility and the fluid friction irreversibility. These two irreversibilities are always opposing. As the heat transfer irreversibility reduces, the fluid friction irreversibility increases. As shown in Fig.15 (a) and 15(b) respectively, the

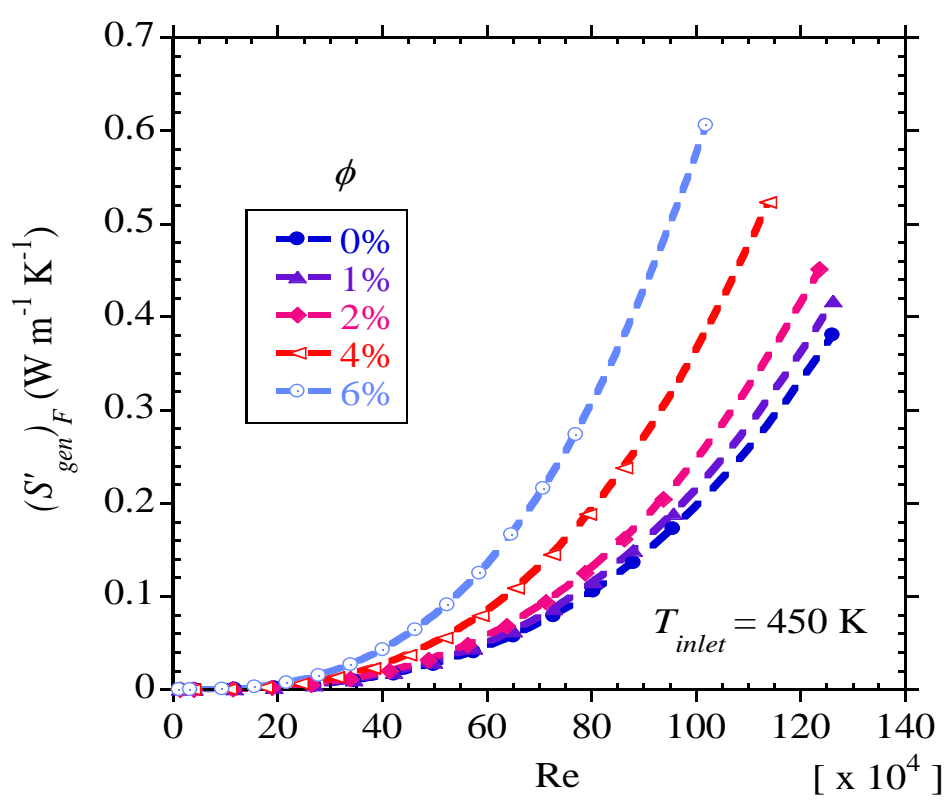

(a)

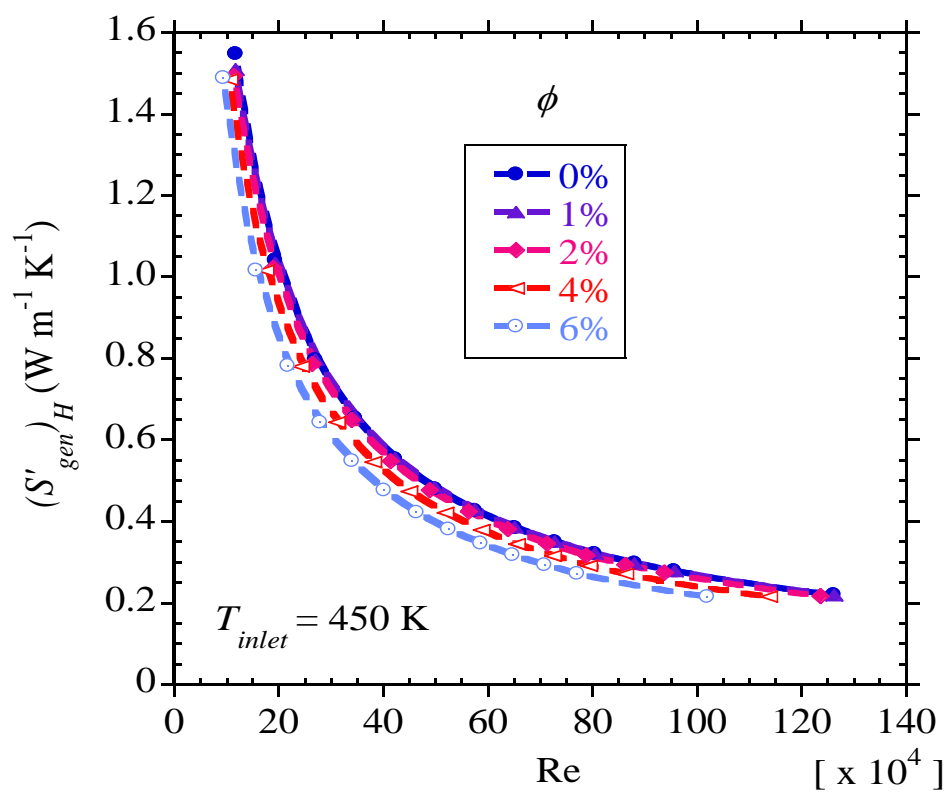

(b)

Fig.15. Entropy generation in the receiver's absorber tube at $450 \mathrm{~K}$ (a) fluid friction irreversibility and (b) heat transfer irreversibility. 
fluid friction irreversibility increases as the Reynolds number and the nanoparticle volume fraction increases while the heat transfer irreversibility reduces as the Reynolds numbers and the nanoparticle volume fractions increase. The reduction in the heat transfer irreversibility is due to lower finite temperature differences with improved heat transfer performance while the increase in the fluid friction is a result of the increased pressure drop and the same trend exists as for pressure drop shown in Figs. 12(a) and 12(b).

The fluid friction irreversibility is shown to be very small at low Reynolds numbers, but increases significantly with nanoparticle volume fraction at higher Reynolds numbers.

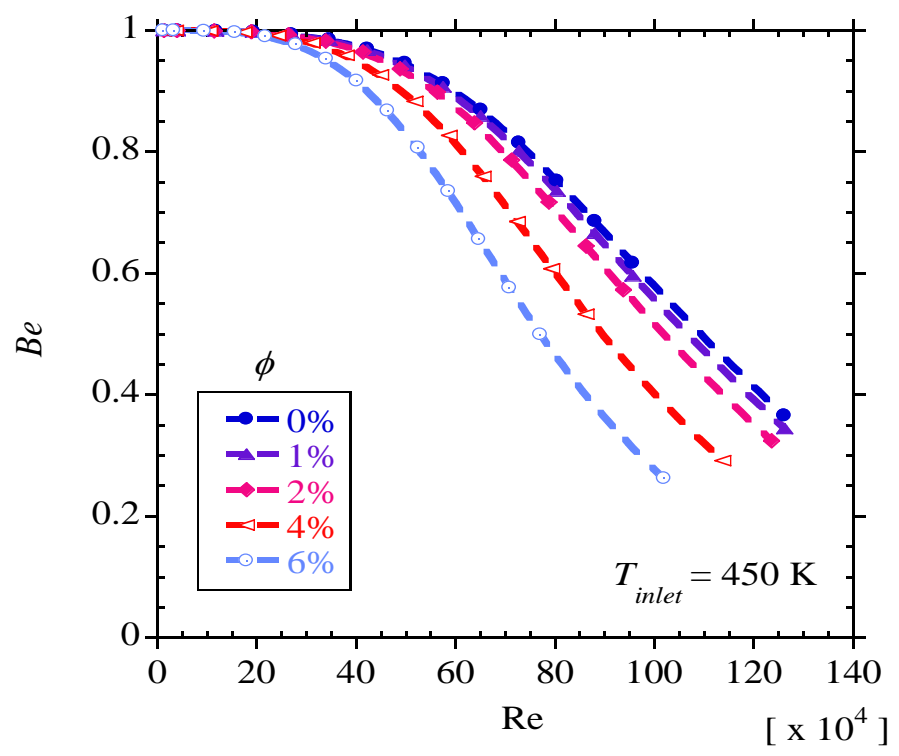

(a)

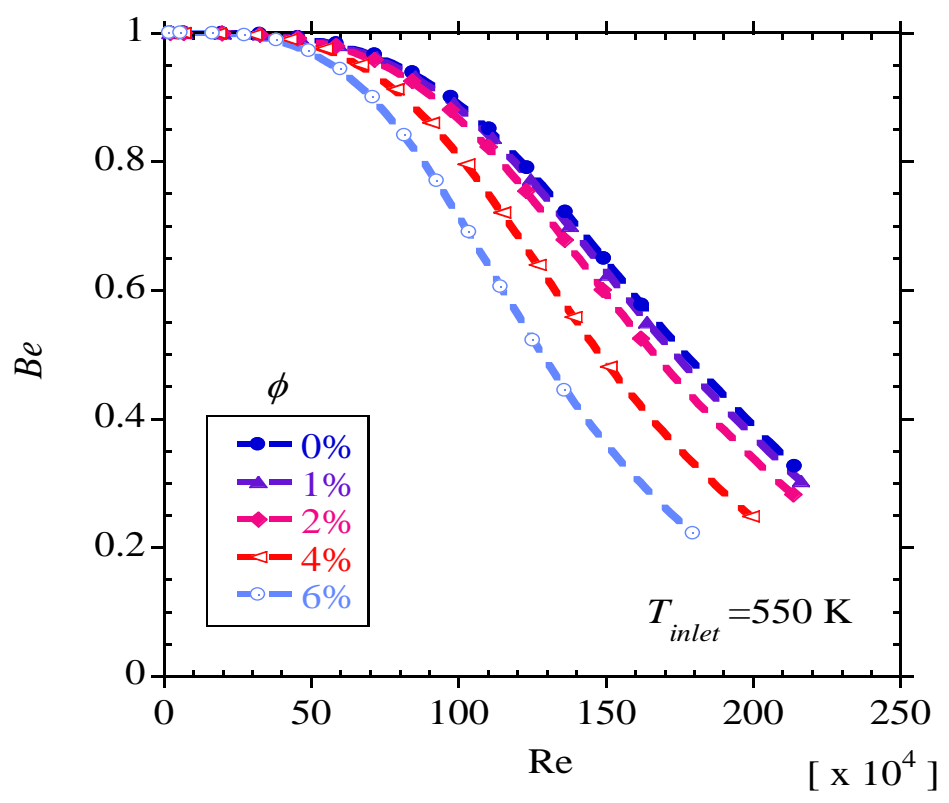

(b)

Fig. 16. Bejan number as a function of Reynolds number and nanoparticle volume fraction at (a) $T_{\text {inlet }}=450 \mathrm{~K}$, and (b) $T_{\text {inlet }}=550 \mathrm{~K}$. 
Conversely, the heat transfer irreversibility is much higher than the fluid friction irreversibility at low Reynolds numbers and reduces with increase in Reynolds number and nanoparticle volume fraction. To show which irreversibility contributes significantly to the entropy generation budget, the Bejan number is used. It is the ratio of the heat transfer irreversibility to the total entropy generation rate. With this definition, if the heat transfer irreversibility is dominant, the Bejan number is close to 1 while if the fluid friction dominates, the Bejan number is close to 0 . The sample variation of Bejan number is shown in Fig. 16 (a) and 16(b) at inlet temperatures of $450 \mathrm{~K}$ and $550 \mathrm{~K}$. As expected, the Bejan number is close to 1 at low Reynolds numbers where the heat transfer irreversibility is dominant. At high Reynolds numbers, the heat transfer irreversibility has reduced and the fluid friction irreversibility has increased significantly, thus, the Bejan number also reduces. Also shown is that the Bejan number reduces with increase in the nanoparticle volume fraction, this is due to improved heat transfer performance as well as increasing pressure drop as volume fraction increases. The same trends shown in these figures exist and can be reproduced at other inlet temperatures.

\subsubsection{Thermodynamic performance with nanofluids}

To show the thermodynamic performance and potential for improved performance, the total entropy generation rate is used in this study. The total entropy generation rate is essentially a combination of the heat transfer and fluid friction irreversibility. As shown in Figs.17 (a) to $17(\mathrm{c})$, for temperatures $400 \mathrm{~K}, 500 \mathrm{~K}$ and $600 \mathrm{~K}$, there is a reduction in the total entropy generation rate with increasing volume fraction up to some Reynolds number. After which, increasing the volume fraction results in entropy generation rates much higher than that in a receiver with $0 \%$ volume fraction (only the base fluid). Flow rates lower than $45 \mathrm{~m}^{3} \mathrm{~h}^{-1}$ guarantee Reynold numbers for which there will always be a reduction in the total entropy generation rate as the nanoparticle volume fraction increases at all inlet temperatures considered in this study.

Consistent with previous investigations [11,69], higher inlet temperatures give lower values of the total entropy generation rate for the same range of flow rates. This is due to the temperature dependent properties used. The heat transfer performance increases as the inlet temperature increase, thus lower heat transfer irreversibilities. Moreover, since the density and viscosity of the heat transfer fluid reduce with increasing temperature, the fluid friction irreversibility also reduces. 


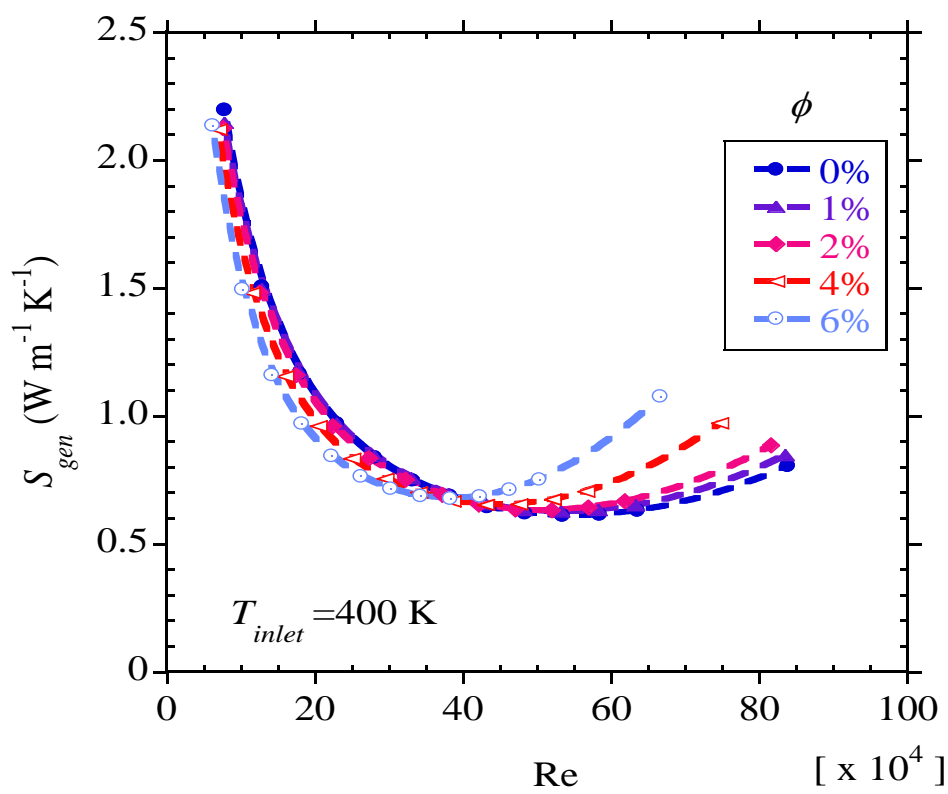

(a)

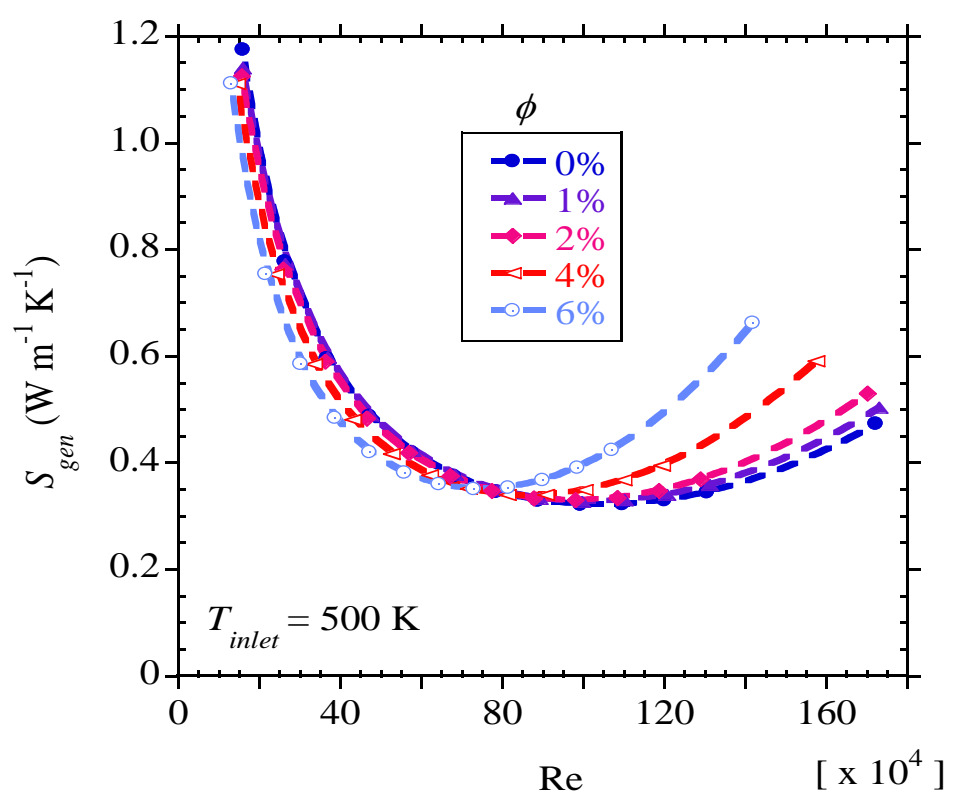

(b) 


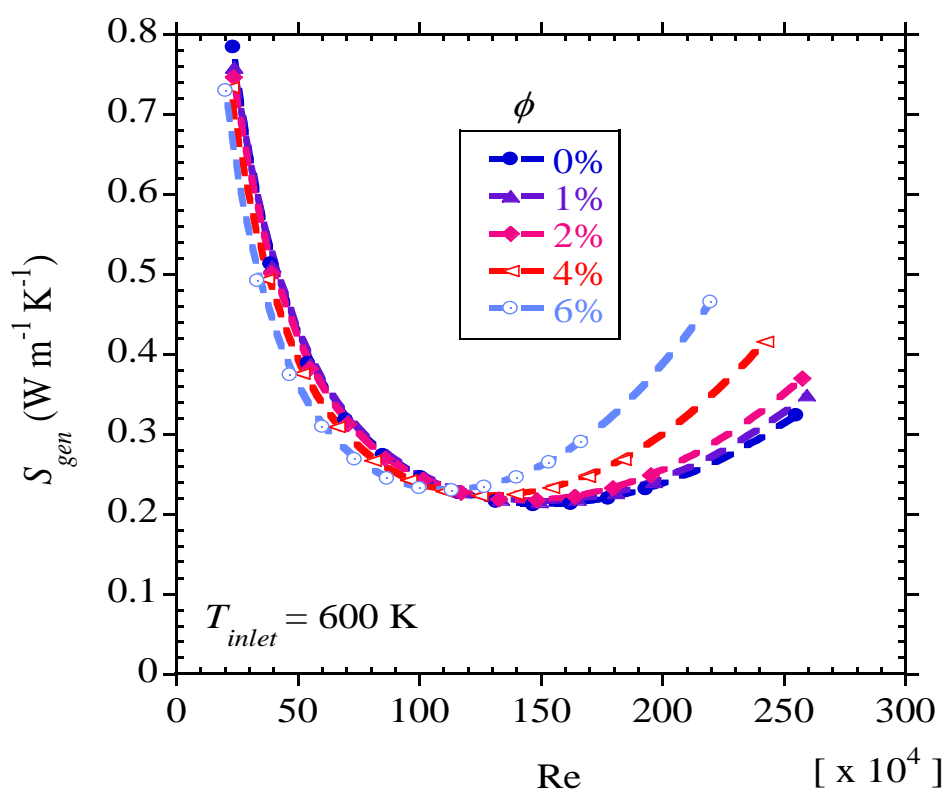

(c)

Fig. 17. Total entropy generation rate as a function of Reynolds number and nanoparticle volume fraction (a)

$$
T_{\text {inlet }}=400 \mathrm{~K} \text {, (b) } 500 \mathrm{~K} \text {, and (c) } 600 \mathrm{~K} \text {. }
$$

In these figures, it is also shown that there is a Reynolds number for which the entropy generation rate is a minimum at each volume fraction an inlet temperature. This arises from the conflicting nature of the heat transfer and fluid friction irreversibilities. The presence of an optimal Reynolds number for which the entropy generation rate is a minimum is clearly shown in Figs. 17(a) - 17c). The optimal Reynolds number decreases as the volume fraction increases. Beyond the optimal Reynolds number, the total entropy generation rate increases with increasing Reynolds number due to much higher increase of the fluid friction irreversibility. Operating at Reynolds numbers beyond this point will not result in any improvement in the receiver thermodynamic performance.

The entropy generation rate reduces by about $30 \%$ as the volume fraction increases from $0 \%$ to $6 \%$ with the largest reductions achievable at the lowest inlet temperature used and when Reynolds numbers are low.

\section{Conclusion}

In this study, the thermal and thermodynamic performance of a parabolic trough receiver using Cu-Therminol ${ }^{\circledR}$ VP-1 as the heat transfer fluid has been presented. The parabolic trough system used in this study has a geometrical concentration ratio of 113 compared to about 82 in the current state of the art systems. The actual heat flux was obtained using ray tracing techniques and coupled to a finite volume based computational fluid dynamics tool for the 
subsequent thermal and thermodynamic analysis. From the study, the following conclusions have been made:

i. The heat transfer performance of the receiver improves as the nanoparticle volume fraction in the base fluid increases. The heat transfer performance is shown to increase by $8 \%, 18 \%$ and $32 \%$ as the nanoparticle volume fraction increases from $0 \%$ to $2 \%, 4 \%$ and $6 \%$, respectively.

ii. Using an expression that incorporates the pumping power in the commonly used equation for thermal efficiency, the thermal efficiency is shown to increase by up to $12.5 \%$ at a volume fraction of $6 \%$. Significant improvements in thermal efficiency are achievable at low flow rates/Reynolds numbers for all temperatures considered. The highest increase in thermal efficiency is obtained at the highest inlet temperature considered.

iii. Using the entropy generation minimisation method, it has been shown that the use of nanofluids improves the thermodynamic performance of the receiver for some range of Reynolds numbers. Beyond a certain Reynolds number using nanofluids makes the entropy generation higher than that in a receiver with only the base fluid. Significant reductions in the entropy generation rates are observable at low Reynolds numbers where the heat transfer irreversibility is much higher than the fluid friction irreversibility. With flow rates lower than $45 \mathrm{~m}^{3} \mathrm{~h}^{-1}$ entropy generation rates reduce between $20-30 \%$ as the volume fraction increases from 0 to $6 \%$.

\section{Acknowledgements}

The support received from the University of the Witwatersrand, Tshwane University of Technology and the University of Pretoria is duly acknowledged and appreciated. The funding received from the National Research Foundation (NRF), the Translational Engineering Skills Programme (TESP), Stellenbosch University, the South African National Energy Research Institute (SANERI)/South African National Energy Development Institute (SANEDI) at the University of Pretoria, the Council for Scientific and Industrial Research (CSIR), the Energy-efficiency and Demand-side Management (EEDSM) Hub and NAC is also duly acknowledged and appreciated.

\section{REFERENCES}

[1] IPCC. Climate Change 2014: Synthesis Report. Contribution of Working Groups I, II and III to the Fifth Assessment Report of the Intergovernmental Panel on Climate Change [Core 
Writing Team, R.K. Pachauri and L.A. Meyer (eds.)]. IPCC, Geneva, Switzerland. IPCC 2014:1-151.

[2] Kalogirou S. Solar energy engineering: processes and systems. 1st ed. Oxford, UK: Elsevier, Academic Press, 2009.

[3] Price H, Lüpfert E, Kearney D, Zarza E, Cohen G, Gee R, Mahoney R. Advances in parabolic trough solar power technology. Sol Energy Eng 2002;124:109-25.

[4] Jebasingh VK, Herbert GMJ. A review of solar parabolic trough collector. Renewable and Sustainable Energy Reviews 2016;54:1085-91.

[5] SunShot Initiative, available at: http://www1.eere.energy.gov/solar/sunshot/index.html. US Department of Energy [accessed 01.02.16].

[6] SunShot Initiative-High-concentration low cost parabolic trough system for baseload CSP, available at: http://www1.eere.energy.gov/solar/sunshot/csp_baseload_skyfuel.html. US Department of Energy [accessed 01.12.13].

[7] Richter C, Teske S, Short R. Concentrating solar power . Greenpeace/SolarPACES/ESTELA 2009; Global outlook 09:1-86.

[8] Schweitzer A, Schiel W, Birkle M, Nava P, Riffelmann KJ, Wohlfahrt A, Kuhlmann G. ULTIMATE TROUGH ${ }^{\circledR}$ - Fabrication, erection and commissioning of the world's largest parabolic trough collector. Energy Procedia 2014;49:1848-57.

[9] Burkholder F, Kutscher C. Heat-loss testing of Solel's UVAC3 parabolic trough receiver. NREL Technical Report 2008; NREL/TP - 550-42394:1-19.

[10] Burkholder F, Kutscher C. Heat loss testing of Schott's 2008 PTR70 parabolic trough receiver. NREL Technical Report 2009; NREL/TP - 550-45633:1-58.

[11] Mwesigye A, Bello-Ochende T, Meyer JP. Minimum entropy generation due to heat transfer and fluid friction in a parabolic trough receiver with non-uniform heat flux at different rim angles and concentration ratios. Energy 2014;73:606-17.

[12] Ravi Kumar K, Reddy KS. Numerical investigation of energy-efficient receiver for solar parabolic trough concentrator. Heat Transfer Eng 2008;29:961-72.

[13] Ravi Kumar K, Reddy KS. Thermal analysis of solar parabolic trough with porous disc receiver. Appl Energy 2009;86:1804-12.

[14] Muñoz J, Abánades A. Analysis of internal helically finned tubes for parabolic trough design by CFD tools. Appl Energy 2011;88:4139-49.

[15] Cheng ZD, He YL, Cui FQ. Numerical study of heat transfer enhancement by unilateral longitudinal vortex generators inside parabolic trough solar receivers. Int J Heat Mass Trans 2012;55:5631-41.

[16] Mwesigye A, Bello-Ochende T, Meyer JP. Heat transfer and thermodynamic performance of a parabolic trough receiver with centrally placed perforated plate inserts. Appl Energy 2014;136:989-1003. 
[17] Mwesigye A, Bello-Ochende T, Meyer JP. Multi-objective and thermodynamic optimisation of a parabolic trough receiver with perforated plate inserts. Appl Therm Eng 2015;77:42-56.

[18] Song X, Dong G, Gao F, Diao X, Zheng L, Zhou F. A numerical study of parabolic trough receiver with nonuniform heat flux and helical screw-tape inserts. Energy 2014;77:771-82.

[19] Das SK. Nanofluids: science and technology. Hoboken, N.J.: Wiley-Interscience, 2008.

[20] Keblinski P, Eastman JA, Cahill DG. Nanofluids for thermal transport. Materials Today $2005 ; 8: 36-44$.

[21] Lee S, Choi SUS, Li S, Eastman JA. Measuring thermal conductivity of fluids containing oxide nanoparticles. ASME J Heat Transfer 1999;121:280-289.

[22] Javadi FS, Saidur R, Kamalisarvestani M. Investigating performance improvement of solar collectors by using nanofluids. Renewable and Sustainable Energy Reviews 2013;28:232-45.

[23] Verma SK, Tiwari AK. Progress of nanofluid application in solar collectors: A review. Energy Conversion and Management 2015;100:324-46.

[24] Turkyilmazoglu M. Performance of direct absorption solar collector with nanofluid mixture. Energy Conversion and Management 2016;114:1-10.

[25] Said Z, Saidur R, Sabiha MA, Hepbasli A, Rahim NA. Energy and exergy efficiency of a flat plate solar collector using $\mathrm{pH}$ treated $\mathrm{Al}_{2} \mathrm{O}_{3}$ nanofluid. J Clean Prod 2016;112, Part 5:3915-26.

[26] Shojaeizadeh E, Veysi F. Development of a correlation for parameter controlling using exergy efficiency optimization of an $\mathrm{Al}_{2} \mathrm{O}_{3}$ /water nanofluid based flat-plate solar collector. Appl Therm Eng 2016;98:1116-29.

[27] Faizal M, Saidur R, Mekhilef S, Alim MA. Energy, economic and environmental analysis of metal oxides nanofluid for flat-plate solar collector. Energy Conversion and Management 2013;76:162-8.

[28] Michael JJ, Iniyan S. Performance of copper oxide/water nanofluid in a flat plate solar water heater under natural and forced circulations. Energy Conversion and Management 2015;95:160-9.

[29] Sabiha MA, Saidur R, Hassani S, Said Z, Mekhilef S. Energy performance of an evacuated tube solar collector using single walled carbon nanotubes nanofluids. Energy Conversion and Management 2015;105:1377-88.

[30] Lu L, Liu Z, Xiao H. Thermal performance of an open thermosyphon using nanofluids for high-temperature evacuated tubular solar collectors: Part 1: Indoor experiment. Solar Energy 2011;85:379-87. 
[31] Liu Z, Hu R, Lu L, Zhao F, Xiao H. Thermal performance of an open thermosyphon using nanofluid for evacuated tubular high temperature air solar collector. Energy Conversion and Management 2013;73:135-43.

[32] Mahian O, Kianifar A, Sahin AZ, Wongwises S. Performance analysis of a minichannelbased solar collector using different nanofluids. Energy Conversion and Management 2014;88:129-38.

[33] Menbari A, Alemrajabi AA, Ghayeb Y. Experimental investigation of stability and extinction coefficient of $\mathrm{Al} 2 \mathrm{O} 3-\mathrm{CuO}$ binary nanoparticles dispersed in ethylene glycol-water mixture for low-temperature direct absorption solar collectors. Energy Conversion and Management 2016;108:501-10.

[34] Taylor AR, Phelan EP, Otanicar PT, Walker AC, Nguyen M, Trimble S, Prasher R. Applicability of nanofluids in high flux solar collectors. Renewable Sustainable Energy 2011;023104:1-15.

[35] Waghole DR, Warkhedkar RM, kulkarni VS, Shrivastva RK. Experimental investigations on heat transfer and friction factor of silver nanofliud in absorber/receiver of parabolic trough collector with twisted tape inserts. Energy Procedia 2014;45:558-67.

[36] Sokhansefat T, Kasaeian AB, Kowsary F. Heat transfer enhancement in parabolic trough collector tube using A12O3/synthetic oil nanofluid. Renewable and Sustainable Energy Reviews 2014;33:636-44.

[37] Mwesigye A, Huan Z, Meyer JP. Thermodynamic optimisation of the performance of a parabolic trough receiver using synthetic oil-Al2O3 nanofluid. Appl Energy 2015;156:398412.

[38] Fuqiang W, Qingzhi L, Huaizhi H, Jianyu T. Parabolic trough receiver with corrugated tube for improving heat transfer and thermal deformation characteristics. Appl Energy 2016;164:411-24.

[39] Incropera PF, DeWitt P,David, Bergman L, Theodore, Lavine S,Adrienne. Fundamentals of heat and mass transfer. 6th ed. US: John Wiley \& Sons, 2006.

[40] ACCURATUS Ceramic corporation. 99.5\% Alumina Material Properties. http://accuratus com/alumox html [accessed 05.10.2015].

[41] Schott PTR ${ }^{\circledR} 70$ receivers, available online at: http://www.schott.com/csp/english/schottsolar-ptr-70-receivers.html [accessed 16.08.2015].

[42] Forristall R. Heat transfer analysis and modeling of a parabolic trough solar receiver implemented in Engineering Equation solver. NREL Technical Report 2003; NREL/TP-55034169:1-145.

[43] ANSYS® Academic research, release 14.5, ANSYS FLUENT, theory guide, ANSYS, Inc.

[44] Shih T, Liou WW, Shabbir A, Yang Z, Zhu J. A new k- $\epsilon$ eddy viscosity model for high reynolds number turbulent flows. Comput Fluids 1995;24:227-38. 
[45] Kock F, Herwig H. Local entropy production in turbulent shear flows: a high-Reynolds number model with wall functions. Int J Heat Mass Trans 2004;47:2205-15.

[46] Kock F, Herwig H. Entropy production calculation for turbulent shear flows and their implementation in cfd codes. Int J Heat Fluid Fl 2005;26:672-80.

[47] Bejan A. Entropy generation minimization: the method of thermodynamic optimization of finite-size systems and finite-time processes. Boca Raton, Fla.: CRC Press, 1996.

[48] Solutia technical bulletin 7239115C-Therminol®VP-, available online at. https://www.therminol.com/products/Therminol-VP1 [accessed 08.09.2015].

[49] Ebrahimi A, Rikhtegar F, Sabaghan A, Roohi E. Heat transfer and entropy generation in a microchannel with longitudinal vortex generators using nanofluids. Energy 2016;101:190201.

[50] Seyf HR, Feizbakhshi M. Computational analysis of nanofluid effects on convective heat transfer enhancement of micro-pin-fin heat sinks. International Journal of Thermal Sciences 2012;58:168-79.

[51] Manca O, Mesolella P, Nardini S, Ricci D. Numerical study of a confined slot impinging jet with nanofluids. Nanoscale Res Lett 2011;6:188,276X-6-188.

[52] Li P, Zhang D, Xie Y. Heat transfer and flow analysis of $\mathrm{Al}_{2} \mathrm{O}_{3}$-water nanofluids in microchannel with dimple and protrusion. Int J Heat Mass Transfer 2014;73:456-67.

[53] Ho CJ, Chen MW, Li ZW. Numerical simulation of natural convection of nanofluid in a square enclosure: Effects due to uncertainties of viscosity and thermal conductivity. Int $\mathbf{J}$ Heat Mass Transfer 2008;51:4506-16.

[54] Roy G, Nguyen CT, Lajoie P. Numerical investigation of laminar flow and heat transfer in a radial flow cooling system with the use of nanofluids. Superlattices and Microstructures 2004;35:497-511.

[55] Maïga SEB, Palm SJ, Nguyen CT, Roy G, Galanis N. Heat transfer enhancement by using nanofluids in forced convection flows. Int J Heat Fluid Flow 2005;26:530-46.

[56] Mahian O, Mahmud S, Heris SZ. Analysis of entropy generation between co-rotating cylinders using nanofluids. Energy 2012;44:438-46.

[57] Buongiorno J, Venerus DC, Prabhat N, McKrell T, Townsend J, Christianson R et al. A benchmark study on the thermal conductivity of nanofluids. J Appl Phys 2009; 106, 094312. doi: $10.1063 / 1.3245330$

[58] SolTrace optical modelling software. SolTrace 2012;2012.7.9.

[59] Wendelin T. Parabolic trough VSHOT optical characterization in 2005-2006. Parabolic trough technology workshop, Incline Village, Nevada, February 14-16, 2006.

[60] Mwesigye A, Le Roux W,Gabriel, Bello-Ochende T, Meyer JP. Thermal and thermodynamic analysis of a parabolic trough receiver at different concentration ratios and 
rim angles. In Proceedings $10^{\text {th }}$ International Conference on Heat Transfer, Fluid Mechanics and Thermodynamics (HEFAT2014) Orlando, Florida, 14-16 July 2014:802-10

[61] SkyTrough ${ }^{\circledR}$ product information: Next-generation solar parabolic tough technology. Available online at: www.skyfuel.com/downloads/brochure/SkyTroughBrochure.pdf [accessed 12.08.2015].

[62] García-Valladares O, Velázquez N. Numerical simulation of parabolic trough solar collector: Improvement using counter flow concentric circular heat exchangers. Int $\mathbf{J}$ Heat Mass Trans 2009;52:597-609.

[63] Mullick SC, Nanda SK. An improved technique for computing the heat loss factor of a tubular absorber. Solar Energy 1989;42:1-7.

[64] ANSYS® Academic research, release 14.5, ANSYS FLUENT user's guide, ANSYS, Inc.

[65] Patankar SV, Spalding DB. A calculation procedure for heat, mass and momentum transfer in three-dimensional parabolic flows. Int J Heat Mass Transfer 1972;15:1787-806.

[66] Çengel YA, Ghajar AJ. Heat and mass transfer: fundamentals \& applications. 4th ed. New York: McGraw-Hill, 2011.

[67] Pak BC, Cho YI. Hydrodynamic and heat transfer study of dispersed fluids with submicron metallic oxide particles. Exp Heat Transfer 1998;11:151-70.

[68] Dudley EV, Kolb JG, Mahoney AR, Mancini T, R., Sloan M, Kearney D. Test results: SEGS LS-2 solar collector. Sandia National Laboratory 1994;SAND94-1884.

[69] Mwesigye A, Bello-Ochende T, Meyer JP. Numerical investigation of entropy generation in a parabolic trough receiver at different concentration ratios. Energy 2013;53:114-27.

[70] Dreyer S, Eichel P, Gnaedig T, Hacker Z, Janker S, Kuckelkorn T, Silmy K, Pernpeintner J, Luepfert E. Heat loss measurements on parabolic trough receivers. SolarPACES 2010.

[71] Mwesigye A, Huan Z. Thermodynamic analysis and optimization of fully developed turbulent forced convection in a circular tube with water-A12O3 nanofluid. Int J Heat Mass Transfer 2015;89:694-706.

[72] Wirz M, Petit J, Haselbacher A, Steinfeld A. Potential improvements in the optical and thermal efficiencies of parabolic trough concentrators. Solar Energy 2014;107:398-414. 